\title{
PANDEMIA E TERRITÓRIO: RITMO DE DIFUSÃO DA COVID-19 ENTRE MUNICÍPIOS BRASILEIROS DE 25 DE FEVEREIRO A 11 DE MAIO DE 2020 DE ACORDO COM FATORES DE PROXIMIDADE SOCIAL EXTRAMUNICIPAL
}

\section{PANDEMIC AND TERRITORY: DIFFUSION RHYTHM OF COVID-19 AMONG BRAZILIAN MUNICIPALITIES FROM FEBRUARY 25 TO MAY 11, 2020 ACCORDING TO EXTRAMUNICIPAL SOCIAL PROXIMITY FACTORS}

\author{
Augusto dos Santos Pereira \\ Doutor em Geografia, Instituto Brasileiro de Geografia e Estatística (IBGE) \\ augustogeog@gmail.com \\ Caroline Busatta Vaz de Paula \\ Doutoranda em Ciências da Saúde, Pontifícia Universidade Católica do Paraná (PUC-PR) \\ carolbvaz@gmail.com \\ Lucia de Noronha \\ Doutora em Medicina (Clínica Cirúrgica), Universidade Federal do Paraná (UFPR) \\ Inno.noronha@gmail.com \\ Eduardo Vedor de Paula \\ Pós-doutor em Ordenamento Territorial, Departamento de Geografia da Universidade Federal do \\ Paraná (UFPR) \\ edugeo@ufpr.br
}

\begin{abstract}
RESUMO
Diante da gravidade da pandemia de COVID-19 e da consequente necessidade de medidas sobre o padrão de difusão territorial da doença para balizamento de tomadas de decisão, o trabalho tem o objetivo de identificar de que forma fatores de proximidade social extramunicipal condicionam o grau de exposição das populações nos diferentes municípios brasileiros ao risco de contaminação por SARS-CoV-2. Para tanto, foram analisados dados referentes a hierarquia urbano-regional, concentração populacional, volume de riqueza, integração territorial por trânsito de bens e pessoas, bem como graus de relevância de turismo, comparando-os com as notificações realizadas entre 25 de fevereiro e 11 de maio de 2020. Os indicadores selecionados, com exceção do PIB per capita, apresentam relação clara com padrões temporais de exposição à introdução do vírus na população dos municípios brasileiros. Observa-se uma lógica topológica de difusão, em que, a despeito da distância, os municípios primeiramente afetados são aqueles com os mais altos graus de proximidade social extramunicipal, sendo seguidos por aqueles em seu entorno imediato. $O$ trabalho contribui com a discussão sobre o padrão de difusão da COVID-19 ao apontar indicadores e limiares que delimitam classes de municípios com distintos graus de exposição ao risco ao longo do tempo.
\end{abstract}

Palavras-Chave: COVID-19. Coronavírus. Indicadores de Gestão Territorial. Proximidade Social.

\begin{abstract}
Given the severity of the COVID-19 pandemic and the consequent need for measures on the pattern of territorial diffusion of the disease, to guide decision-making, the study aims to identify how factors of extra-municipal social proximity condition the degree of exposure of populations in different Brazilian municipalities to the risk of contamination by SARS-CoV-2. Therefore, through data science and geoprocessing tools, data regarding urban-regional hierarchy, population concentration, volume of wealth, territorial integration by transit of goods and people, as well as degrees of relevance of tourism were analyzed, comparing them with the notifications made between February 25 and May 11, 2020. The selected indicators, except for GDP per capita, present a clear relationship with temporal patterns of exposure to the introduction of the virus in the population of Brazilian municipalities. A
\end{abstract}

Recebido em: 27/05/2020

Aceito para publicação em: 18/08/2020. 
Pandemia e território: ritmo de difusão da Covid-19 entre municípios brasileiros de 25 de fevereiro a 11 de maio de 2020 de acordo com fatores de proximidade social extramunicipal
Augusto dos Santos Pereira Caroline Busatta Vaz de Paula Lucia de Noronha

Eduardo Vedor de Paula

topological logic of diffusion is observed, in which, despite the distance, the municipalities first affected are those with the highest degrees of extramunicipal social proximity, being followed by those in their immediate surroundings. As a result, the work contributes to the discussion about the diffusion pattern of COVID-19 by pointing out indicators and thresholds that delimit classes of municipalities with different levels of exposure to risk over time.

Keywords: COVID-19. Coronavirus. Territorial Management Indicators. Social Proximity.

\section{INTRODUÇÃO}

Em meio à pandemia de COVID-19, com diversos casos nacionais e internacionais de colapso de sistemas de saúde, e diante do drástico crescimento do número de novos casos e de óbitos no Brasil, além de seus efeitos nos hábitos quotidianos e condições socioeconômicas (ONU, 2020), emerge a necessidade de parâmetros que informem a sociedade e autoridades públicas sobre medidas de prevenção em graus variados de risco de contaminação (OMS, 2020a).

Com vistas à melhor alocação de recursos, à orientação de protocolos de medidas por parte de diversos atores (prefeituras, empresas, agentes de saúde etc.), as autoridades de saúde necessitam de informações consistentes acerca do padrão espaço-temporal de evolução da epidemia; de modelos de sua distribuição territorial em cenários futuros; de pressão sobre infraestrutura para atendimento de saúde; além de efeitos socioeconômicos, em especial sobre as parcelas mais vulneráveis da população, como aqueles dependentes de programas de assistência social, os moradores de favelas e outros tipos de ocupações irregulares ou aqueles que fazem parte do elevado contingente de desempregados no atual cenário econômico.

Nesse contexto, o território municipal encontra-se em evidência na política de enfrentamento da expansão da COVID-19, uma vez que ela se encontra altamente embasada em recomendações de isolamento social, proibição de aglomerações, além do fechamento de comércios e serviços nãoessenciais, o que demanda decisão precisa dos gestores locais, além de lançar inúmeras incertezas sobre o futuro próximo para a vida social, econômica e para a saúde pública no seu interior.

Diante desse cenário, o presente trabalho foi construído a partir do objetivo de identificar de que forma fatores de proximidade social extramunicipal condicionam o grau de exposição das populações nos diferentes municípios brasileiros ao risco de contaminação por SARS-CoV-2.

O recorte de análise são os municípios brasileiros. O Brasil apresenta 5.570 desses entes federativos de terceiro grau, que contam com sua autonomia política, administrativa e orçamentária, dotados de competência sobre assuntos de interesse local, com limites territoriais nos quais deve haver, legalmente, uma sede urbana. Usualmente sua jurisdição se encontra também em área rural, com poucos exemplos de municípios que apresentam $100 \%$ de área urbana.

Tal exercício se justifica pela necessidade de identificação do comportamento de variáveis que possam servir para a modelagem da disseminação geográfica da epidemia em tela; pela necessidade de geração de informação para tomadores de decisão; e pela necessidade de monitoramento do desenvolvimento geográfico da epidemia, sobretudo em momentos futuros, em que será necessário identificar métodos seguros de relaxamento gradual de medidas de distanciamento/isolamento social.

A hipótese, diante desse quadro, foi de que medidas de hierarquia urbano-regional, concentração populacional, volume de riqueza, integração territorial por trânsito de bens e pessoas, bem como graus de relevância de turismo conformam indicadores que delimitam grupos de municípios com diferentes graus de exposição ao risco de inserção da COVID-19 em seu território em menor intervalo de tempo.

\section{FUNDAMENTAÇÃO TEÓRICA}

Com vistas a atingir o objetivo de identificar a forma como fatores de proximidade social extramunicipal condicionam o grau de exposição das populações nos diferentes municípios brasileiros ao risco de contaminação por SARS-CoV-2, adiante encontra-se uma revisão da literatura sobre as características infecciosas, epidemiológicas e clínicas da COVID-19, bem como de conceitos da Geografia da Saúde pertinentes à sua análise. 
Pandemia e território: ritmo de difusão da Covid-19 entre municípios brasileiros de 25 de fevereiro a 11 de maio de 2020 de acordo com fatores de proximidade social extramunicipal
Augusto dos Santos Pereira Caroline Busatta Vaz de Paula Lucia de Noronha Eduardo Vedor de Paula

\section{Características Infecciosas, Epidemiológicas e Clínicas da COVID-19}

Em 31 de dezembro de 2019, 27 casos de pneumonia com etiologia desconhecida surgiram em Wuhan, província de Hubei, China. Quatro dias após o surgimento dos primeiros relatos (03/01/20), o número de casos dessa doença havia subido para 44. No dia 07 de janeiro de 2020, um novo tipo de coronavírus foi identificado na amostra de nasofaringe de um paciente pelas autoridades chinesas. Esse vírus respiratório, posteriormente, seria denominado de SARS-CoV-2, causador da doença intitulada COVID-19 (GE et al., 2020). No dia 11 de março do corrente ano, dada a rápida expansão do novo coronavírus pelo mundo e sua presença em cerca de 114 países, a Organização Mundial da Saúde (OMS) declarou estado de pandemia (WHO, 2020).

O número de pessoas acometidas pelo SARS-CoV-2 tem crescido de forma exponencial desde o surto da COVID-19, até a propagação mundial (HUANG et al., 2020). A relação entre um paciente sabidamente infectado e o número de pessoas que este paciente consegue infectar, ou seja a taxa de transmissibilidade de um vírus (número básico de reprodução - R0), é comumente utilizada para estimar a média do número de casos secundários gerados a partir do caso primário em uma população suscetível (LANA, 2020). A taxa de transmissibilidade é reflexo, principalmente das características biológicas do vírus bem como da suscetibilidade do hospedeiro. As estimativas de R0 para SARS-CoV-2, variam de 1,6 a 4,1, isto é, cada paciente positivo para SARS-CoV-2 poderia contaminar em média, entre 1 a 4 pessoas (READ et al., 2020; LIU et al., 2020). Quando comparado com o Influenza A H1N1pdm09, observa-se que esta variação (R0) gira em torno de 1,3 e 1,8, o que justificaria a tamanha disseminação da atual pandemia (INFOGRIPE, 2020).

Pacientes com COVID-19 podem apresentar quadros clínicos variáveis, desde infecções assintomáticas e leves ( $80 \%$ dos casos), a infecções graves e críticas (15 e $5 \%$ dos casos respectivamente) (ROKNI et al., 2020). Nos casos assintomáticos, não há qualquer sintoma clínico, porém o teste de PCR (do inglês reverse-transcriptase polymerase chain reaction) para SARS-CoV-2 é positivo. A progressão para quadros graves de COVID-19 pode levar principalmente a sintomas respiratórios. No entanto, sintomas cardiovasculares, gastrointestinais, neurológicos, hematológicos, entre outros têm sido descritos (ROTHAN; BYRAREDDY, 2020; VELAVAN; MEYER, 2020). Já nos casos críticos, o paciente pode vir a apresentar principalmente síndrome de angústia respiratória aguda (SARA) e alterações vasculares trombogênicas, exigindo o suporte de uma Unidade de Terapia Intensiva com a necessidade, entre outras, de ventilação mecânica e anticoagulação terapêutica (ZHANG et al., 2020). A mortalidade de adultos nos casos críticos pode ser superior a $50 \%$ (BULUT; KATO, 2020).

A pandemia de SARS-CoV-2 é única tendo em vista algumas peculiaridade notáveis do vírus, como a sua alta afinidade com receptores que são expressos por quase todos os tipos celulares do corpo humano, chamados receptores da angiotensina-convertase-enzima-2 (ACE-2) o que multiplica muito a sua capacidade de infecção e de produzir doença, aumentando as chances de contaminação de outros indivíduos (ROTHAN; BYRAREDDY, 2020). Além disso, as proteínas de superfície do SARSCoV-2 (spike proteins) são proteínas muito glicosiladas e por isso apresentam baixa imunogenicidade o que dificulta o seu reconhecimento pelo sistema imunológico do paciente, aumentando ainda mais o tempo de doença e o de eliminação de partículas virais pelos infectados, perpetuando assim a pandemia. Em terceiro lugar, seu possível recente salto de um animal para os humanos determina uma taxa de $100 \%$ de suscetíveis, visto que a população mundial, como um todo não havia ainda entrado em contato com o SARS-CoV-2. Por último, a alta viabilidade no ambiente externo e, finalmente, a resposta imune adaptativa atrasada ao vírus significam que os pacientes são vetores desse vírus por longos períodos. Sendo assim, todos esses fatores podem contribuir para a disseminação rápida e sustentada do vírus (COSSARIZZA et al., 2020).

\section{COVID-19, Proximidade Social e o Espaço Geográfico}

Para a análise da difusão territorial da COVID-19, cujas características infecciosas, epidemiológicas e clínicas foram expostas acima, é relevante que se realize uma suscinta revisão do conceito de espaço geográfico e do papel da pesquisa em Geografia da Saúde, o que deve embasar a identificação dos caminhos metodológicos pertinentes ao objetivo do presente trabalho.

Nesse sentido, é preciso se destacar que os estudos de Geografia da Saúde têm crescido no Brasil nas últimas décadas (JUNQUEIRA, 2009). No que tange aos trabalhos relacionados ao comportamento geográfico de doenças infecto-parasitárias, a contribuição da disciplina tem sido ainda mais marcante a partir da constatação de que modelos uni-causais, baseados apenas na 
Pandemia e território: ritmo de difusão da Covid-19 entre municípios brasileiros de 25 de fevereiro a 11 de maio de 2020 de acordo com fatores de proximidade social extramunicipal
Augusto dos Santos Pereira Caroline Busatta Vaz de Paula Lucia de Noronha Eduardo Vedor de Paula

exposição a agentes etiológicos, são insuficientes para a explicação da difusão dessas doenças, o que requer uma abordagem multicausal, em que as condições ambientais e sociais sejam levadas em conta (LEMOS; LIMA, 2002).

De fato, a concepção de espaço tomada nos estudos de saúde e epidemiologia atestam um movimento que parte de um cenário inicialmente mais biológico e natural, estático, para um mais suscetível a alterações, até uma concepção que reifica o papel das dinâmicas sociais em suas relações com as condições naturais (SILVA, 1997).

Assim sendo, fatores sociais (acesso a atendimento de saúde, condições socioeconômicas, infraestrutura, entre tantos outros), associados às condições ambientais e aos fatores etiológicos, com sua particular distribuição geográfica, são considerados nas análises sobre a incidência de doenças infectocontagiosas. Isso traz particular atenção sobre o quadro urbano, em que, muitas vezes, condições socioeconômicas precárias se associam a um ambiente significativamente adensado e com problemas de saneamento básico, em que condições de insalubridade podem ser facilitadoras no processo de difusão de doenças.

Nessa perspectiva, a distribuição desigual dos diversos objetos geográficos, tanto naturais como sociais, gera um contexto caracterizado por condições geográficas que contribuem para diferentes níveis de exposição das populações a fatores desencadeadores de doenças infectocontagiosas. Isso não se dá somente a partir da localização desses objetos, mas de sua interconexão, por inúmeros tipos de trânsito, sobretudo de pessoas.

Por essa razão, é pertinente a concepção de Milton Santos (1978), para quem o espaço geográfico é formado por fixos e fluxos, ou seja, por objetos geográficos (cidades, fazendas, pontes, estações de metrô, infraestruturas, florestas, bosques, praças etc.), e por deslocamentos e intercâmbios (informação, comandos, significados culturais, energia, bens, capital, pessoas etc.), de tal forma que as dinâmicas sociais condicionam o espaço, ao mesmo tempo que por ele são condicionadas, dialeticamente.

Assim, entende-se que os condicionamentos do espaço geográfico sobre os processos sociais podem ser uma chave explicativa particularmente importante para a presente pesquisa, uma vez que os estudos apontam para a premência de dinâmicas da sociedade no processo de difusão da epidemia de COVID-19, sobretudo no que tange a questões de proximidade/afastamento social.

O monitoramento da COVID-19 em centenas de países e os estudos científicos relacionados sugerem que, em meio à inexistência de vacina ou de tratamento medicamentoso de elevada eficácia para o impedimento de morbidade grave, ou para recuperação rápida do paciente, há uma relevância das estratégias de afastamento/isolamento social para controle da doença (OMS, 2020c; LEWNARD; LO, 2020). Conforme a OMS:

Medidas de distanciamento social e físico visam a retardar a propagação da doença pela interrupção de cadeias de transmissão do COVID-19 e impedindo que novas apareçam. Essas medidas garantem distância física entre as pessoas (de pelo menos um metro) e reduzem o contato com superfícies contaminadas, ao mesmo tempo que incentivam e sustentam a conexão social virtual dentro das famílias e comunidades. As medidas para o público em geral incluem a introdução de arranjos de trabalho flexíveis, como teletrabalho, ensino a distância, redução de aglomeração, fechamento de instalações e serviços não essenciais, blindagem e proteção para grupos vulneráveis, restrições de movimento local ou nacional e medidas de permanência em casa, e reorganização coordenada das redes de saúde e serviços sociais para proteger os hospitais. As medidas são utilizadas em conjunto com medidas protetivas individuais contra o COVID-19, como lavagem frequente das mãos e etiqueta da tosse (OMS, 2020c, s/p.).

Assim, ao se reconhecer o espaço geográfico não somente como produto da sociedade, mas como um condicionante de seus processos e dinâmicas, tem-se que diversos fixos e fluxos que caracterizam esse espaço podem servir de elemento explicativo tanto para a proximidade social, como para a consequente difusão territorial de uma doença altamente infecciosa como a COVID-19.

Nesse sentido, é possível se conceber que fatores como hierarquia urbana, patamar populacional, produção de riqueza, infraestrutura para transporte de passageiros, mobilidade de cargas e o turismo, desigualmente distribuídos entre os municípios brasileiros, podem compor fatores que permitem maior ou menor proximidade social entre os residentes de cada um dos territórios municipais com

DOI: http://dx.doi.org/10.14393/Hygeia16055064 $\quad$ Hygeia $\quad$ v.16 $\quad$ p. 199-219, 2020 página 202


Pandemia e território: ritmo de difusão da Covid-19 entre municípios brasileiros de 25 de fevereiro a 11 de maio de 2020 de acordo com fatores de proximidade social extramunicipal
Augusto dos Santos Pereira Caroline Busatta Vaz de Paula Lucia de Noronha Eduardo Vedor de Paula

indivíduos residentes alhures, seja no Brasil ou no exterior. Por essa razão, no presente trabalho, elementos geográficos que indiquem potencial aumento de interação entre populações para além dos limites municipais são chamados de fatores de proximidade social extramunicipal.

\section{MATERIAIS E MÉTODOS}

Tendo-se observado que a COVID-19 é uma doença com alta transmissibilidade, o que reifica a importância de condições geográficas que promovem maiores níveis de proximidade social física, foi adotada uma metodologia calcada no agrupamento de municípios segundo fatores de proximidade social extramunicipal e identificação da proporção de municípios afetados (ao menos um caso notificado) nesses grupos, entre 25 de fevereiro e 11 de maio de 2020, conforme boletins de casos confirmados. Para operacionalização da pesquisa, foram utilizadas as fontes de dados, etapas de trabalho, técnicas e recursos descritos adiante.

\section{Dados e Fontes}

Para a contagem do número de casos, utilizou-se o levantamento feito por COTA (2020), que leva em conta as notificações contabilizadas nos boletins de cada estado brasileiro. Pela utilização dessa fonte, visou-se a que o trabalho contornasse possíveis temeridades no trato dos dados da epidemia por parte de autoridades, como foi apontado por matérias jornalísticas nacionais e internacionais, como se pode ver em BBC NEWS (2020).

Além dos casos notificados por município brasileiro, buscaram-se outros dados que possam compor verdadeiros fatores de proximidade social extramunicipal, ou seja, elementos que afetam o grau segundo o qual indivíduos da população residente em um município têm possibilidade de entrar em contato social mediado por proximidade física com aqueles residentes em outros municípios brasileiros, ou mesmo no exterior, o que é considerado elemento de exposição ao risco de introdução da COVID-19 no município. Nesse sentido, foram utilizadas medidas de hierarquia urbana, patamar populacional, produção de riqueza, trânsito de mercadorias, transporte de passageiros e turismo.

Assim, optou-se por utilizar os dados de hierarquia urbana dos centros urbanos ligados a cada município como um dos fatores de proximidade social extramunicipal. Em estudos urbano-regionais, o conceito de hierarquia urbana, foi desenvolvido a partir da contribuição de autores como Walter Christaller (1933), Berry e Garrison (1958) e Rochefort (1966), significando a estrutura de distintos graus de centralidade em uma rede urbana, de maneira que a crescentes níveis de complexidade de serviços correspondem maiores áreas de influência dos centros urbanos. Dessa forma, a região de influência formada por essa integração urbana em rede é o espaço de trânsito de conhecimento, de recursos e, também, de pessoas, com as mais diversas finalidades (negócios, compras, lazer, atendimento de saúde, serviços públicos etc.), fenômeno que será tanto maior quanto mais expressiva for a complexidade e a capacidade de atração dos maiores centros urbanos.

Nesse ínterim, foram obtidos dados do estudo Regiões de Influência das Cidades - REGIC, elaborado pelo Instituto Brasileiro de Geografia e Estatística (IBGE, 2008), que é a base em que se encontram as análises sobre a rede urbana do Brasil e sua configuração em onze classes hierárquicas: grande metrópole nacional; metrópoles nacionais; metrópoles; capitais regionais $(A, B$ e $C$ ); centros sub-regionais ( $\mathrm{A}$ e $\mathrm{B}$ ); centros de zona ( $\mathrm{A}$ e $\mathrm{B}$ ) e centros locais.

Entre as medidas que podem auxiliar a identificar fatores de proximidade social extramunicipal, considerou-se que maiores patamares populacionais significam, na prática, aumento do número de pessoas que, em suas diversas atividades quotidianas, podem contatar pessoas residentes alhures. De fato, a relação entre patamar populacional e a disseminação da COVID-19 já foi identificada em trabalhos como o de Heroy (2020), que identificou que as cidades com maiores patamares populacionais tendem a chegar primeiro nas fases mais agudas do ciclo epidêmico. Assim sendo, utilizou-se a estimativa de população municipal, a partir dos dados oficiais do IBGE (2019).

Além do fator populacional, é de se esperar que a dimensão econômica tenha relação importante com a difusão de uma pandemia como a COVID-19. As atividades econômicas podem ser fatores geradores de complementaridades territoriais, com diferentes níveis de fluxos entre os municípios, no interior dos países, e deles com o exterior, o que pode corresponder diferentes níveis de proximidade social extramunicipal. Assim, foram geradas classes de municípios por tamanho do seu Produto Interno Bruto - PIB - e por PIB per capita, para 2017, conforme dados do IBGE (2017).

Ainda por conta da ênfase do presente trabalho em classificar os municípios a partir de condições que possam gerar maiores níveis de proximidade social para além os limites municipais, pareceu

DOI: http://dx.doi.org/10.14393/Hygeia16055064 Hygeia $\quad$ v.16 $\quad$ p. $199-219,2020$ página 203


Pandemia e território: ritmo de difusão da Covid-19 entre municípios brasileiros de 25 de fevereiro a 11 de maio de 2020 de acordo com fatores de proximidade social extramunicipal
Augusto dos Santos Pereira Caroline Busatta Vaz de Paula Lucia de Noronha Eduardo Vedor de Paula

conveniente a identificação do volume de trânsito de mercadorias entre os municípios do Brasil, e deles com o exterior. Produtos diversos partem e chegam aos municípios por diversos modais, tais como dutos (no caso de derivados de petróleo, por exemplo), trens, navios, aviões e caminhões, alguns desses mobilizando uma quantidade significativa de pessoas em trânsito, que, eventualmente, podem se tornar vetores de transmissão de doenças infectocontagiosas. No que tange às trocas comerciais entre municípios brasileiros, no entanto, tem-se restrição de acesso aos dados por sigilo fiscal das bases do Imposto sobre Circulação de Mercadorias e Prestação de Serviços - ICMS. Por outro lado, os dados de exportação/importação dos municípios são acessíveis em plataforma do Ministério da Economia, Indústria, Comércio Exterior e Serviços (MDIC, 2020).

Avançando sobre fatores de proximidade social extramunicipal, parece bastante razoável a concepção de que ela seja também condicionada pela mobilidade de pessoas por meio dos serviços de transporte de passageiros. Em relação aos serviços rodoviários e hidroviários, optou-se por utilizar o índice de proximidade, medida que visa a identificar quanto cada nó na rede rodoviária/hidroviária está ligado aos demais, por número de viagens de passageiros, conforme a pesquisa de Ligações Rodoviárias e Hidroviárias (IBGE, 2016).

A respeito dos dados sobre transporte aeroviário, foi utilizada a base da Agência Nacional de Aviação Civil (ANAC, 2020), que informa o número de passageiros em trânsito em cada aeroporto no Brasil. Ressalva-se que, em alguns casos, a base de dados foi alterada, de maneira que os passageiros de alguns municípios, foram atribuídos a outros, que tendem a ter maior proporção de participação efetiva nas origens e destinos. Assim, passageiros de Guarulhos e de São José dos Pinhais, por exemplo, foram atribuídos a São Paulo e Curitiba, respectivamente.

Por fim, optou-se por utilizar dados de turismo como um fator de proximidade social extramunicipal. Para tanto, foi feito uso de base do Ministério do Turismo (2019). O órgão classifica os municípios com participação no turismo nacional em cinco classes de relevância, tendo como critério o número de estabelecimentos e de trabalhadores formais no setor de hospedagem, mais estimativas do número de turistas (MINISTÉRIO DO TURISMO, 2020). As classes de relevância do turismo vão de $A$, a mais alta, até a $E$, a mais baixa.

É importante salientar que os dados elencados têm origem em fontes oficiais consistidas. Quanto às notificações, entende-se que um intervalo de tempo adequado foi abrangido a ponto de permitir que o baixo número de testes praticados não configurasse um viés para os resultados.

Cabe mencionar ainda que, por convenção internacional, as semanas epidemiológicas são contadas de domingo a sábado. A primeira semana do ano é aquela que contém o maior número de dias do novo ano (PORTAL SINAN, 2020). Assim, no Brasil o primeiro caso de COVID-19 foi confirmado e registrado na nona semana epidemiológica de 2020. Ante o exposto, para facilidade argumentativa sobre as datas e períodos em que ocorrem o processo de difusão territorial da COVID-19, a data de 25 de fevereiro é considerada, no estudo, como início da primeira semana do evento. Ressalva-se, ainda, que as datas de notificação não correspondem às datas de transmissão/infecção.

\section{Etapas de trabalho, técnicas e recursos}

O fluxo de trabalho foi caracterizado por etapas de obtenção, tratamento, análise de dados, bem como divulgação dos resultados. Em cada etapa, foram aplicadas técnicas estatísticas, de Ciência de Dados e de geoprocessamento expostas no Quadro 1.

Quadro 1 - Etapas e técnicas utilizadas

\begin{tabular}{|l|l|}
\hline \multicolumn{1}{|c|}{ Etapa } & \multicolumn{1}{c|}{ Técnica } \\
\hline Obtenção & $\begin{array}{l}\text { Geração de algoritmo de obtenção automática de dados on-line (webscraping) e sua } \\
\text { transformação em padrão matricial, condizente com operações tabulares. }\end{array}$ \\
\hline Tratamento & $\begin{array}{l}\text { Identificação de valores duplicados, outliers e faltantes. Compatibilização e junção de dados de } \\
\text { diferentes bases a partir de indexação por código municipal do IBGE. }\end{array}$ \\
\hline Análise & $\begin{array}{l}\text { Análise exploratória e análise de comportamento temporal por exploração visual a partir de } \\
\text { gráficos e mapas. }\end{array}$ \\
\hline Divulgação & Elaboração de ambiente interativo, on-line, de acesso público em Pereira (2020). \\
\hline
\end{tabular}

Fonte: Elaborado pelo Autor 
Pandemia e território: ritmo de difusão da Covid-19 entre municípios brasileiros de 25 de fevereiro a 11 de maio de 2020 de acordo com fatores de proximidade social extramunicipal
Augusto dos Santos Pereira Caroline Busatta Vaz de Paula Lucia de Noronha Eduardo Vedor de Paula

Entre os recursos computacionais utilizados para a viabilização desse estudo, destacam-se o software de geoprocessamento ArcGIS 9.3.2, as bibliotecas Pandas, Matplotlib, Seaborn e Geopandas, em linguagem Python, para tratamento e análise de dados tabulares, além de plotagem de gráficos e de mapas temáticos. Foram utilizados Jupyter notebooks, ambientes de programação interativa, para geração dos códigos-fonte e disponibilização pública on-line.

\section{RESULTADOS: SUCESSÃO DAS PRIMEIRAS NOTIFICAÇÕES MUNICIPAIS EM RELAÇÃO ÀS MEDIDAS DE PROXIMIDADE SOCIAL EXTRAMUNICIPAL}

Adiante são apresentados os resultados da pesquisa, com a identificação das semanas do evento epidêmico em que houve a primeira notificação em cada município afetado, ao longo do período analisado, em comparação com as medidas de proximidade social extramunicipal levantadas.

\section{Ritmo de difusão da Epidemia de COVID-19 entre municípios brasileiros}

Após quase três meses de difusão notificada de COVID-19 em diversos países, o Brasil apresentou sua primeira notificação, em São Paulo, no dia 25 de fevereiro de 2020. Em 11 de maio de 2020, apenas 76 dias após a primeira notificação, o Brasil já registrava 169.099 casos acumulados (COTA, 2020), com 11.123 óbitos e 67.384 recuperados (MS, 2020). Trata-se de um crescimento significativamente acelerado, o que, na data, colocava o Brasil entre os dez países com maior número de notificações no mundo (OMS, 2020b). O Gráfico 1 mostra a quantidade diária e acumulada de municípios com casos notificados no país.

\section{Gráfico 1 - Incremento diário do número de municípios com casos notificados no Brasil}

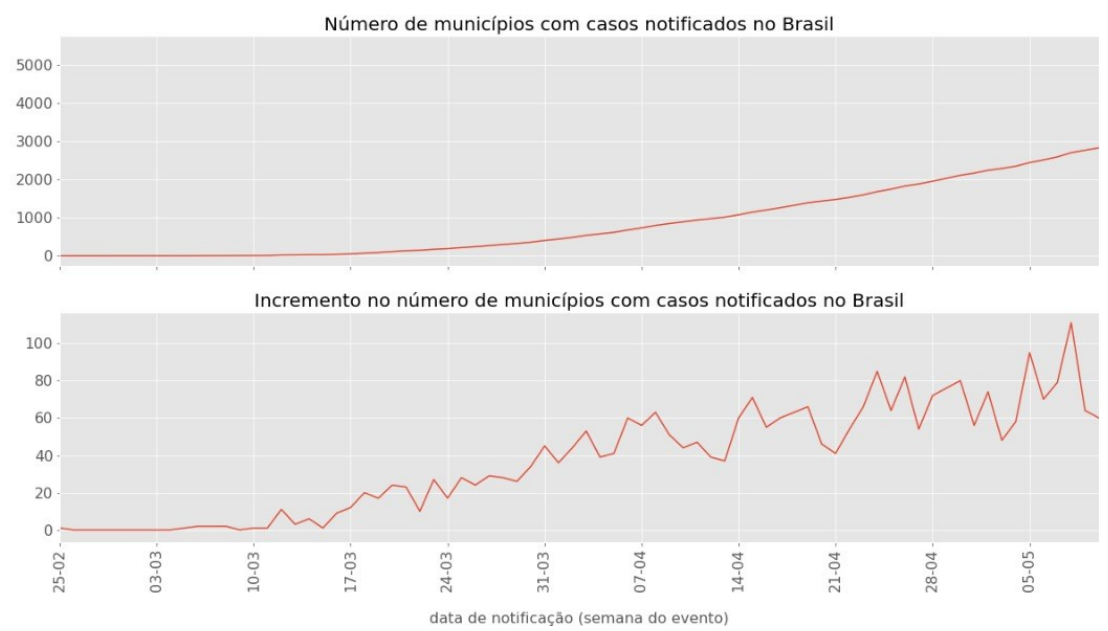

Fonte: Elaborado por Augusto dos Santos Pereira a partir de dados disponíveis em IBGE (2008) e COTA (2020) Nota: O gráfico ignora uma minoria de casos reportados nos quais não há identificação dos municípios.

No que tange à difusão territorial da COVID-19, nota-se que, no período de setenta e sete dias em análise, houve notificações em 2.820 municípios, 50,6\% dos 5.570 municípios brasileiros, conforme o Gráfico 1. É possível observar, também, que, até a data, havia uma tendência de crescimento do número de novos municípios afetados por dia. Assim, em todo o período, houve uma média de 37 novos municípios atingidos pela COVID-19 diariamente, ao passo que, entre 1 e 11 de maio de 2020, esse valor médio foi de 71 novos municípios com seu primeiro caso notificado. A distribuição dos municípios afetados pode ser vista na Figura 1. 
Pandemia e território: ritmo de difusão da Covid-19 entre municípios brasileiros de 25 de fevereiro a 11 de maio de 2020 de acordo com fatores de proximidade social extramunicipal
Augusto dos Santos Pereira Caroline Busatta Vaz de Paula Lucia de Noronha

Eduardo Vedor de Paula

Figura 1 - Municípios brasileiros segundo a semana do evento em que houve a primeira notificação

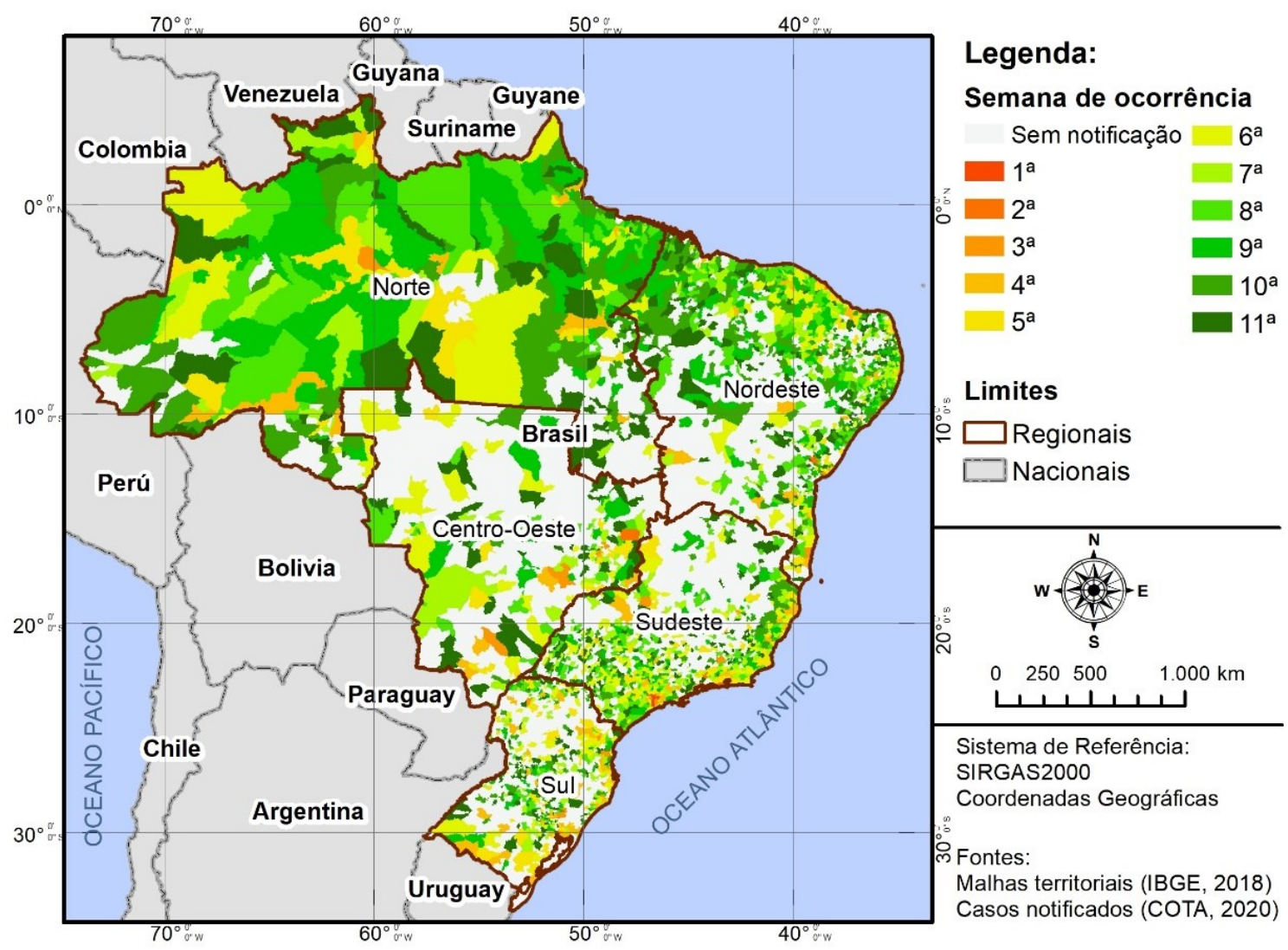

Fonte: Elaborado por Augusto dos Santos Pereira.

A Figura 1 mostra que os casos de COVID-19 se encontravam distribuídos em municípios de todas as regiões do país, com algumas porções territoriais ainda sem notificações e com grande predominância de áreas contaminadas a partir da sexta semana do evento (a partir de 31 de março de 2020).

\section{Difusão da COVID-19 entre os municípios segundo Hierarquia Urbana}

A fim de identificar o papel da hierarquia urbana no controle da exposição das populações de diferentes municípios ao risco de contaminação, foi elaborado o Gráfico 2, que mostra a proporção de municípios afetados por dia, segundo a hierarquia urbana a que estão associados. $\mathrm{O}$ eixo vertical indica a razão de municípios por classe, com máximo em 1, o que denota $100 \%$ dos municípios de dada hierarquia com notificação em uma determinada data, representada no eixo horizontal. Fica evidente, por meio do Gráfico 2, que existem ritmos bastante distintos de registros de COVID-19 de acordo com a hierarquia urbana. De maneira geral, é possível se notar, ao longo do tempo, uma tendência de participação incremental da proporção municípios com casos notificados conforme o aumento de sua hierarquia. 
Pandemia e território: ritmo de difusão da Covid-19 entre municípios brasileiros de 25 de fevereiro a 11 de maio de 2020 de acordo com fatores de proximidade social extramunicipal
Augusto dos Santos Pereira Caroline Busatta Vaz de Paula Lucia de Noronha Eduardo Vedor de Paula

Gráfico 2 - Razão de municípios com casos notificados por total de municípios no Brasil, segundo hierarquia urbana associada

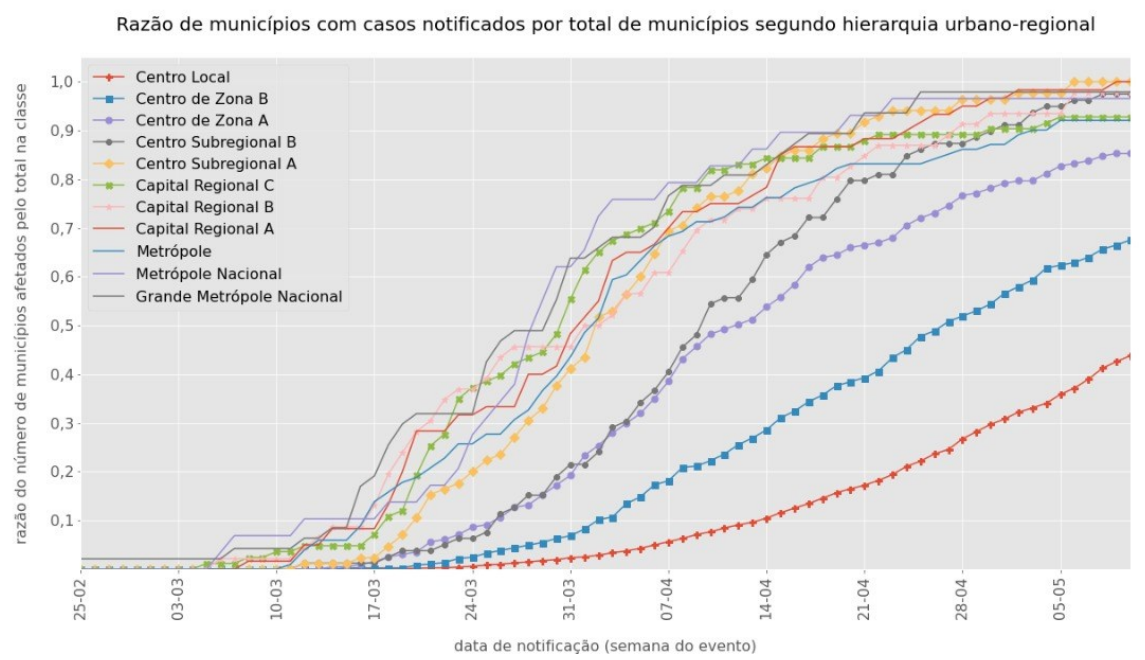

Fonte: Elaborado por Augusto dos Santos Pereira a partir de dados disponíveis em IBGE (2008) e COTA (2020) Nota: O gráfico ignora uma minoria de casos reportados nos quais não há identificação dos municípios.

Quatro grupos com ritmos bastante distintos são identificados. Um primeiro grupo é formado pelos municípios ligados à grande metrópole nacional (São Paulo), às metrópoles nacionais (Brasília e Rio de Janeiro), às metrópoles com influência regional (Manaus, Belém, Fortaleza, Recife, Salvador, Belo Horizonte, Curitiba, Goiânia e Porto Alegre $)^{2}$, capitais regionais (A, B e C), além de centros subregionais A. Esse primeiro grupo apresentava entre 85,3 e $100 \%$ de seus municípios com casos notificados de COVID-19 em 11 de maio de 2020, com um ritmo de crescimento bastante superior durante todo o período de presença de casos no Brasil. Um segundo grupo é formado por municípios ligados a centros sub-regionais $B$ e centros de zona $A$, que chegaram a proporções de territórios com notificações tão elevadas quanto o primeiro grupo, mas em intervalo de tempo maior, por vezes de quinze dias. Os municípios dos centros de zona B foram afetados, proporcionalmente, em ritmo inferior, demorando, por vezes, vinte dias, para chegar na razão municípios afetados/total de municípios atingida por aqueles do primeiro grupo. Em 11 de maio, $67,5 \%$ desses municípios tinham casos registrados. Por fim, os municípios dos centros locais foram atingidos posteriormente, em relação àqueles das demais categorias de hierarquia urbana. Em 11 de maio, 43,8\% desses municípios haviam sido afetados. É preciso ressalvar, no entanto, que essa é a classes com o maior número de municípios, o que significa um grande número absoluto de territórios afetados (1963 municípios).

Por meio da Figura 2, é possível observar, para um conjunto de municípios dos estados do Rio de Janeiro, Minas Gerais e São Paulo, que, de fato, essas unidades territoriais foram afetadas em momentos distintos, segundo sua hierarquia urbana.

2 O IBGE (2008) considera as metrópoles (grande nacional, nacionais e regionais) como seus polos e classifica os municípios da aglomeração metropolitana como áreas de concentração de população. Tendo em vista a finalidade do presente trabalho de indicar ritmos de propagação dos casos de COVID-19 entre os municípios de diferentes grupos/classes, aqueles pertencentes ao entorno metropolitano foram classificados como metrópole. Assim, a indicação de quase $80 \%$ dos municípios da metrópole nacional com notificação na última data se refere a todos os municípios daquele aglomerado, conforme a classificação do estudo do instituto. 
Pandemia e território: ritmo de difusão da Covid-19 entre municípios brasileiros de 25 de fevereiro a 11 de maio de 2020 de acordo com fatores de proximidade social extramunicipal
Augusto dos Santos Pereira Caroline Busatta Vaz de Paula Lucia de Noronha Eduardo Vedor de Paula

Figura 2 - Parcela dos municípios dos estados do Rio de Janeiro, São Paulo e Minas Gerais, segundo semana do evento em que houve a primeira notificação e a hierarquia urbano-regional

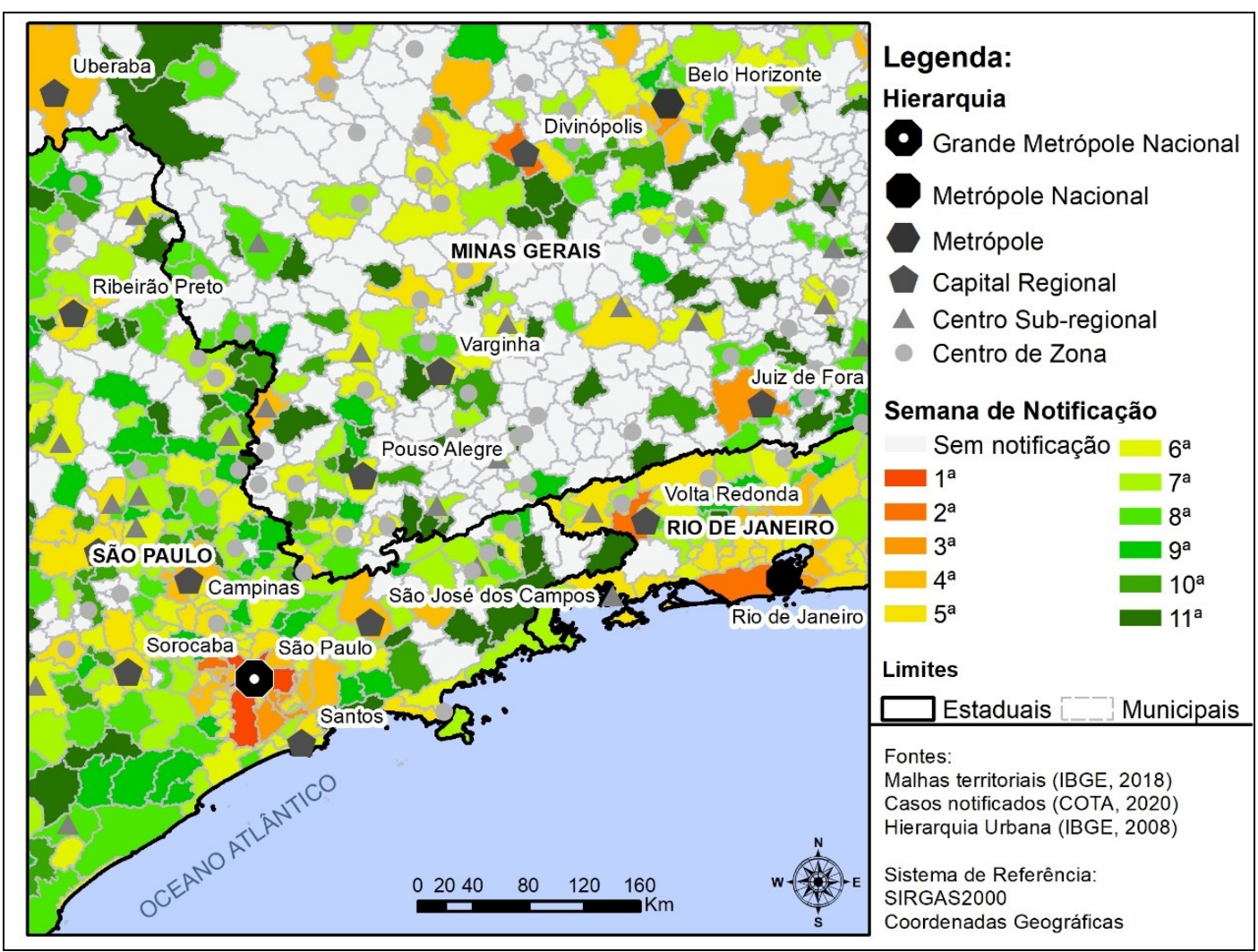

Fonte: Elaborado por Augusto dos Santos Pereira.

As metrópoles representadas na Figura 2, tiveram casos contabilizados no início da instalação da pandemia no Brasil. São Paulo teve casos na primeira semana, sendo, de fato, o primeiro município com casos notificados, enquanto o município do Rio de Janeiro foi afetado na semana seguinte, e Belo Horizonte na quarta semana.

Diversos municípios metropolitanos foram atingidos subsequentemente. No entorno de São Paulo, trinta e um municípios foram atingidos entre a segunda e a quinta semana do evento, entre os quais Ferraz de Vasconcelos, Carapicuíba, Mauá, São Caetano do Sul, Santo André, São Bernardo do Campo, Guarulhos, Osasco, Barueri, Cotia, Suzano, Vargem Grande Paulista e Mogi das Cruzes.

Ao redor do Rio de Janeiro, Niterói, Guapimirim, São Gonçalo, Duque de Caxias, Belford Roxo, Itaboraí, Nova Iguaçu, Maricá, Queimados, São João do Meriti, Mesquita, Magé e Nilópolis, entre outros municípios, também já apresentavam suas primeiras notificações antes de 30 de março, último dia da quinta semana da epidemia.

Entre os municípios pertencentes ao espaço metropolitano de Belo Horizonte, Sete Lagoas, Nova Lima, Betim, Contagem, Sabará, Santa Luzia, Ribeirão das Neves, Esmeraldas e Sarzedo tiveram suas primeiras notificações ainda no mês de março de 2020.

Uma espécie de controle da hierarquia urbana parece se delinear, também, quando se avança para as capitais regionais representadas na Figura 2. Em Minas Gerais, Uberaba, Uberlândia, Divinópolis e Juiz de Fora tiveram seus primeiros casos de COVID-19 notificados entre a segunda e quarta semanas. Varginha e Pouso Alegre, por sua vez, entraram para esse rol na quinta semana.

No Estado de São Paulo, capitais regionais importantes também foram afetadas ainda no mês de março. São José dos Campos e Campinas apresentaram notificações na $4^{a}$ semana a partir do primeiro caso registrado no Brasil, ao passo que Piracicaba, Sorocaba e Santos tiveram casos na 
Pandemia e território: ritmo de difusão da Covid-19 entre municípios brasileiros de 25 de fevereiro a 11 de maio de 2020 de acordo com fatores de proximidade social extramunicipal
Augusto dos Santos Pereira Caroline Busatta Vaz de Paula Lucia de Noronha Eduardo Vedor de Paula

semana seguinte. Em todos esses casos, os municípios do entorno tiveram notificações, usualmente, em datas posteriores.

\section{Difusão da COVID-19 entre os municípios segundo Patamar Populacional}

Para a análise da relação entre difusão da COVID-19 e os patamares populacionais dos municípios, optouse por classes de até 20 mil (3.796 municípios), 50 mil (1.101), 100 mil (349), 500 mil (276), um milhão de habitantes (31) e acima (17 municípios), buscando-se agrupamentos segundo ordens de grandeza significativamente distintas, que possam encerrar dinâmicas urbanas e de integração específicas, o que, consequentemente, poderia interferir em seus graus de proximidade social extramunicipal. Dessa forma, a fração dos municípios assim classificados pode ser observada no Gráfico 3.

\section{Gráfico 3 - Razão de municípios com casos notificados por total de municípios no Brasil, segundo} número de habitantes em 2019

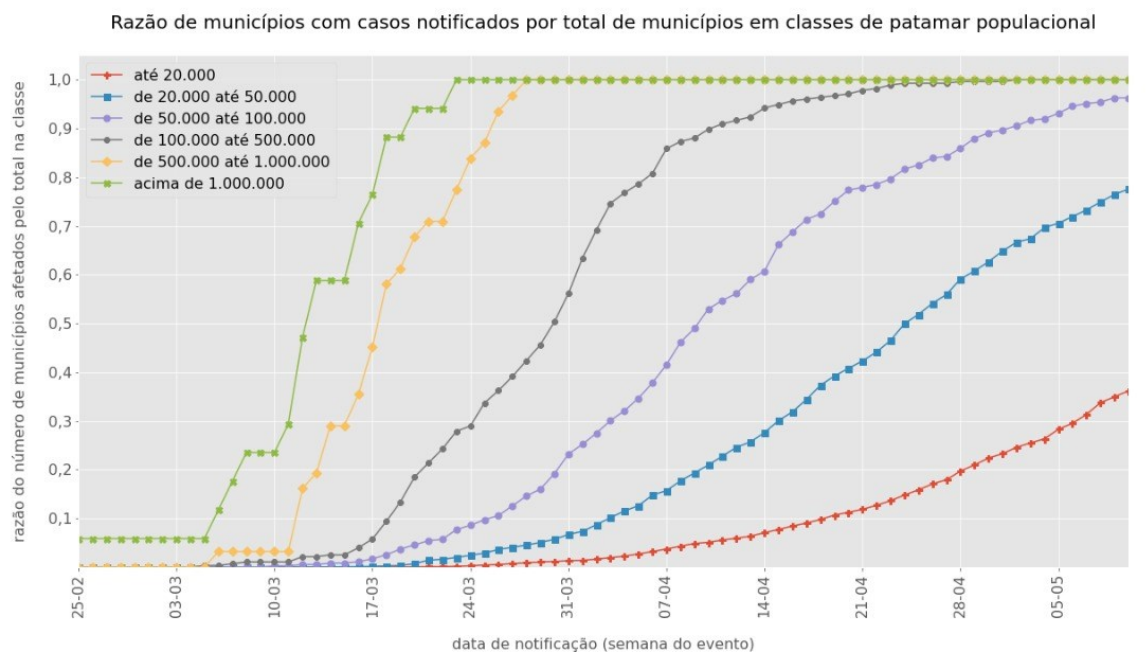

Fonte: Elaborado por Augusto dos Santos Pereira a partir de dados disponíveis em IBGE (2019) e COTA (2020)

Nota: O gráfico ignora uma minoria de casos reportados para os quais não há identificação dos municípios.

Por meio do Gráfico 3, é possível observar que os dois grupos de municípios com número de habitantes a partir de 500 mil tiveram uma vertiginosa participação, de maneira que, no intervalo de aproximadamente um mês, nenhum desses 48 municípios se ausentavam de notificação. Houve destaque também entre os municípios com população entre 100 mil e menos de 500 mil habitantes (276 municípios), que foram todos afetados no intervalo de dois meses. Quase todos os 349 municípios com população entre 50 e 100 mil habitantes foram afetados, o que levou, porém, todo o período analisado para ocorrer. Durante o período, foram afetados pela epidemia aproximadamente $78,8 \%$ dos 1.101 municípios com população superior a 20 mil e até 50 mil habitantes. Já os 3.796 municípios com população inferior a 20 mil habitantes tiveram um período de baixa suscetibilidade às notificações até 05 de abril. Desde então houve uma notável aceleração de sua participação entre aqueles com contaminações, chegando em 10 de maio a 1.374 municípios $(37,3 \%)$.

\section{Difusão da COVID-19 entre os municípios segundo Nível de Produção de Riqueza}

Tendo em vista a necessidade de avaliação da difusão da COVID-19 entre municípios brasileiros, segundo classes de produção de riqueza, foi elaborado o Gráfico 4, em que é possível observá-los agrupados em seis faixas de PIB: até $R \$ 50$ milhões (693 municípios); mais de $R \$ 50$ a $R \$ 100$ milhões (1.109); mais de $R \$ 100$ a $R \$ 500$ milhões (2.447), mais de $R \$ 500$ milhões a $R \$ 1$ bilhão (561); acima de $R \$ 1$ a $R \$ 5$ bilhões (597); acima de $R \$ 5$ a $R \$ 10$ bilhões (65); acima de $R \$ 10$ a $R \$$ 20 bilhões (56); acima de $\mathrm{R} \$ 20$ bilhões (42).

Essas classes foram criadas considerando a manutenção de intervalos de grandeza suficientes para caracterizar uma mudança relevante de produção de riqueza entre classes e de maneira a garantir uma mínima representatividade de municípios em seu interior. 
Pandemia e território: ritmo de difusão da Covid-19 entre municípios brasileiros de 25 de fevereiro a 11 de maio de 2020 de acordo com fatores de proximidade social extramunicipal
Augusto dos Santos Pereira Caroline Busatta Vaz de Paula Lucia de Noronha Eduardo Vedor de Paula

Gráfico 4 - Razão de municípios com casos notificados por total de municípios no Brasil, segundo PIB (R\$ milhões) em 2017

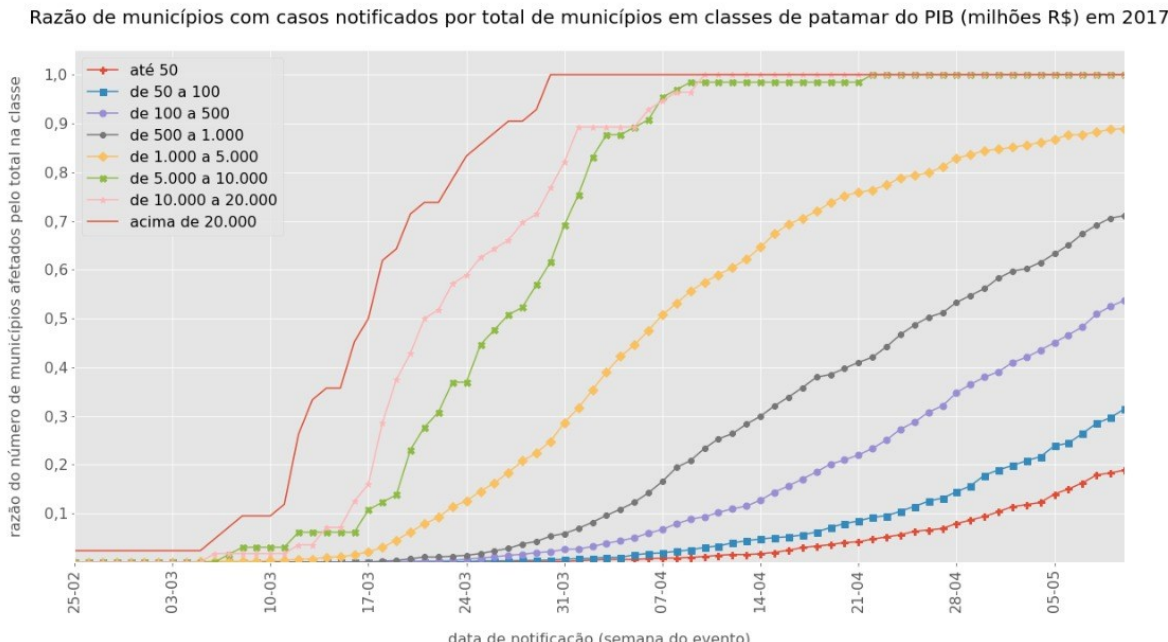

Fonte: Elaborado por Augusto dos Santos Pereira a partir de dados disponíveis em IBGE (2017) e COTA (2020) Nota: O gráfico ignora uma minoria de casos reportados nos quais não há identificação dos municípios.

Pelo Gráfico 4, nota-se que as três primeiras classes, cujos municípios apresentam PIB acima de $\mathrm{R} \$ 5$ bilhões, tiveram ritmo de exposição, segundo casos notificáveis, muito superior às demais, sendo aquela que tinha $100 \%$ de seus municípios afetados (163) até 11 de maio de 2020. Os 597 municípios com PIB entre 1 e 5 bilhões de reais foram atingidos significativamente, de maneira que 89,6\% deles já apresentavam casos até aquela data. As quatro classes municipais restantes mantiveram esse padrão de menor proporção de municípios afetados no final do período analisado.

Assim, como as medidas de hierarquia urbana e de população parecem ter uma forte relação com o processo de difusão das primeiras notificações de COVID-19 entre os municípios brasileiros, vê-se que existe também uma relação importante com o PIB municipal. Para identificar se esse comportamento persiste em relação ao volume de riqueza produzido e normalizado por número de habitantes, os municípios brasileiros foram agrupados em classes de PIB per capita, expostas no Gráfico 5.

Gráfico 5 - Razão de municípios com casos notificados por total de municípios no Brasil, segundo PIB per capita em $2017(\mathrm{R} \$)$

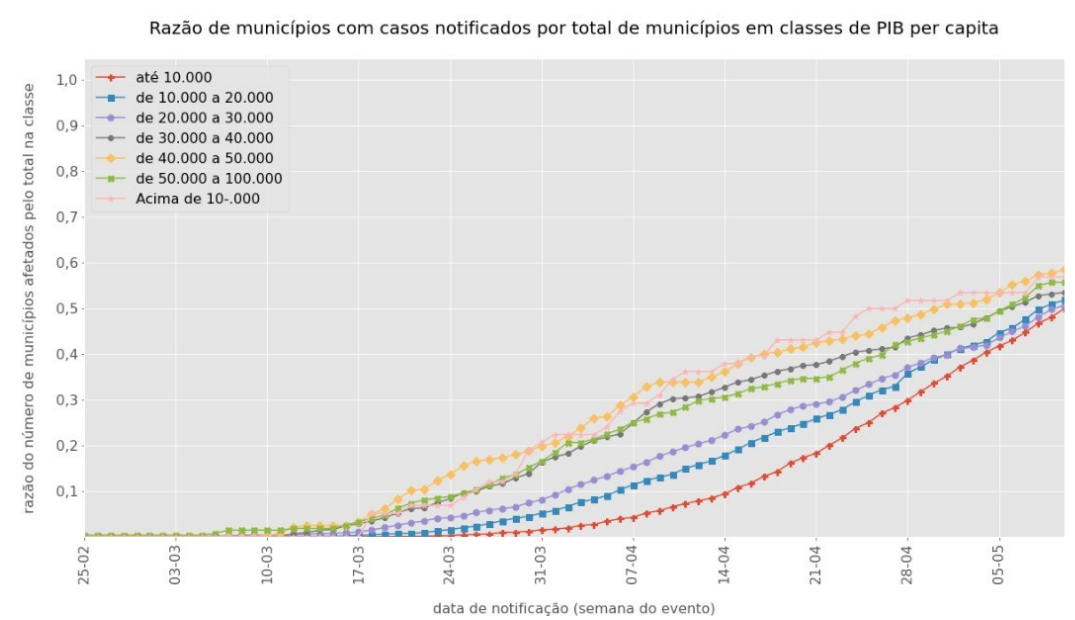

Fonte: Elaborado por Augusto dos Santos Pereira a partir de dados disponíveis em IBGE $(2017 ; 2019)$ e COTA (2020)

Nota: O gráfico ignora uma minoria de casos reportados nos quais não há identificação dos municípios.

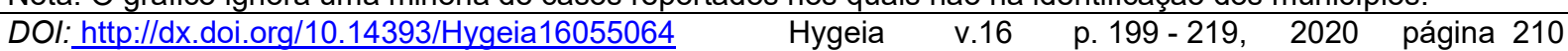


Pandemia e território: ritmo de difusão da Covid-19 entre municípios brasileiros de 25 de fevereiro a 11 de maio de 2020 de acordo com fatores de proximidade social extramunicipal
Augusto dos Santos Pereira Caroline Busatta Vaz de Paula Lucia de Noronha

Eduardo Vedor de Paula

Dos 5.570 municípios brasileiros, 1.541 tinham PIB per capita de até $\mathrm{R} \$ 10$ mil; 1.748 tinham acima de $R \$ 10$ a $R \$ 20$ mil, 1.126 de $R \$ 20$ a $R \$ 30$ mil, 594 com mais de $R \$ 30$ a $R \$ 40$ mil, 277 com mais de $R \$ 40$ a $R \$ 50$ mil, 271 com mais de $R \$ 50$ a $R \$ 100$ mil e, por fim, 58 municípios com PIB per capita acima dos $\mathrm{R} \$ 100$ mil.

Nota-se que essa relação da difusão da COVID-19 com o nível de riqueza parece estar mais ligada ao volume bruto, uma vez que a diferença de exposição das populações nos municípios em diferentes classes de PIB per capita não se mostra tão distinta ao longo do tempo, conforme mostra o Gráfico 5.

\section{Difusão da COVID-19 entre os municípios segundo Volume de Exportações e Importações}

Dado que parte significativa do trânsito de mercadorias pode servir como fator de mobilidade de pessoas entre os municípios, gerando proximidade social extramunicipal e exposição da população municipal ao SARS-CoV-2, o ritmo de difusão da COVID-19 entre municípios foi analisado em relação aos volumes de exportações e de importações.

É preciso destacar que a distribuição das exportações no Brasil é bastante desigual. No ano de 2019, 3.374 municípios não apresentavam qualquer volume exportado; 274 , até U\$ 50 mil; 179 , entre U\$ 50 e U\$ 200 mil; 161, entre U\$ 200 e U\$ 500 mil; 177, entre U\$ 500 mil e U\$ 1 milhão; 344, entre 1 e U\$ 5 milhões; 347, entre 5 e U\$ 20 milhões; 237, entre 20 e U\$ 50 milhões; 177, entre 50 e U\$ 100 milhões; 232, entre 100 e U\$ 500 milhões; 93 acima de U\$ 500 milhões. A proporção de municípios afetados nessas classes, por data de notificação, encontra-se no

Gráfico 6.

Gráfico 6 - Razão de municípios com casos notificados por total de municípios no Brasil, segundo volume de exportações em 2019 (U\$ FOB)

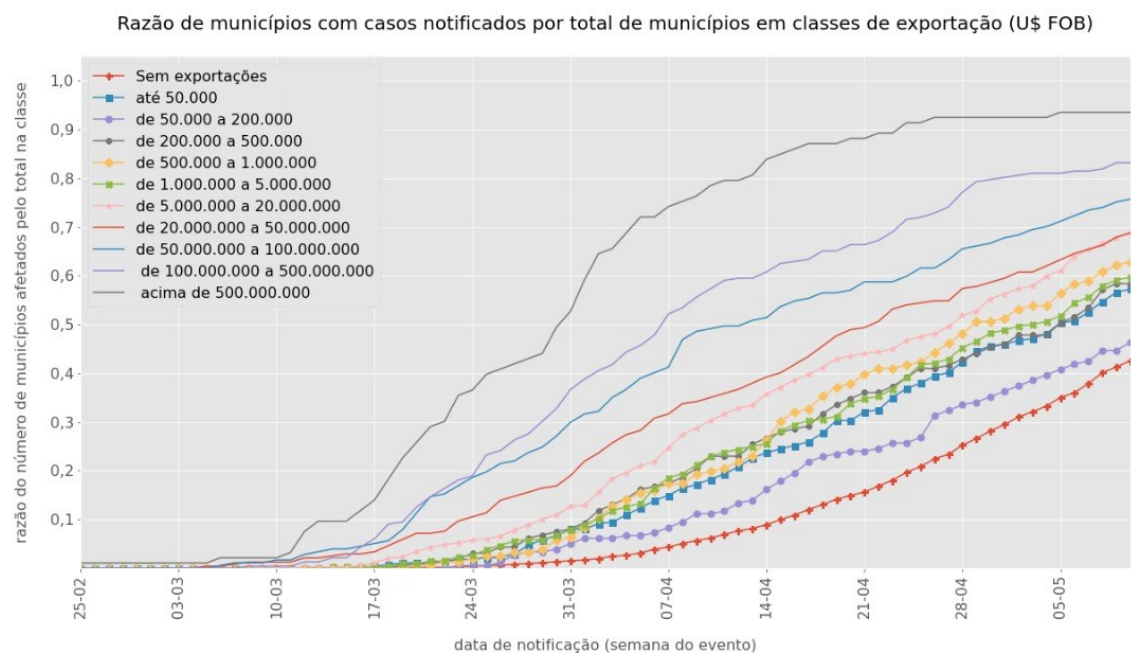

Fonte: Elaborado por Augusto dos Santos Pereira a partir de dados disponíveis em MDIC (2020) e COTA (2020)

Nota: O gráfico ignora uma minoria de casos reportados nos quais não há identificação dos municípios.

Novamente um padrão hierárquico é notável no processo de difusão da COVID-19 entre os municípios brasileiros, com destaque para os quase cem municípios com exportação superior a $\mathrm{R} \$$ 500 milhões, atingidos em $93,6 \%$, com decréscimo gradual de participação relativa intraclasse, até aquela sem exportação, que contou com $43,7 \%$ dos seus municípios (1.475 municípios) afetados, considerando-se a data de referência.

No que tange às importações, foram criadas as seguintes classes: sem importação (3.548 municípios); até U\$ 50.000 (420), acima de 50.000 até U\$ 100.000 (115); acima de 100.000 até U\$ 500.000 (283), acima de 500.000 até U\$ 1.000 .000 (140); acima de 1.000 .000 até U\$ 5.000 .000 (364), acima de 5.000 .000 até U\$ 10.000 .000 (163); acima de 10.000 .000 até U\$ 50.000 .000 (26); 
Pandemia e território: ritmo de difusão da Covid-19 entre municípios brasileiros de 25 de fevereiro a 11 de maio de 2020 de acordo com fatores de proximidade social extramunicipal
Augusto dos Santos Pereira Caroline Busatta Vaz de Paula Lucia de Noronha

Eduardo Vedor de Paula

acima de 50.000.000 até U\$200.000.000 (134); acima de 2000.000.000 até U\$ 500.000.000 (64); acima de U\$500.000.000 (75), apresentadas no Gráfico 7.

O Gráfico 7 mostra como as classes acima de U\$ 200 milhões em importação tiveram mais de $100 \%$ de seus 139 municípios afetados pela COVID-19 até a data de referência, seguidos pela classe imediatamente inferior (entre 50 e U\$ 200 milhões), com quase 95,5\% de municípios (128 de 134) afetados e pela classe de 10 a U\$ 50 milhões, com $84,4 \%$ de municípios com registros de COVID-19 (223 de 264).

Gráfico 7 - Razão de municípios com casos notificados por total de municípios no Brasil, segundo volume de importações em 2019 (U\$ FOB)

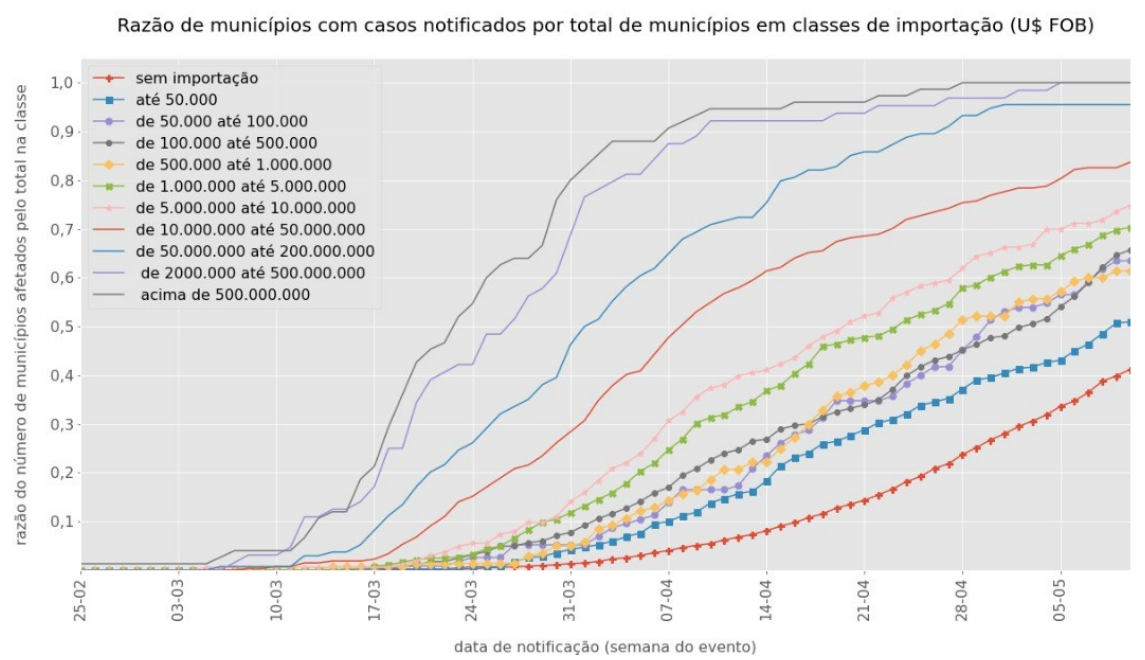

Fonte: Elaborado por Augusto dos Santos Pereira a partir de dados disponíveis em MDIC (2020) e COTA (2020) Nota: O gráfico ignora uma minoria de casos reportados nos quais não há identificação dos municípios.

A difusão da epidemia teve um grande processo de aceleração em direção aos municípios das demais classes de importação, sobretudo a partir do final de março de 2020, avançando, inclusive sobre aqueles sem registro de importação. Ante o exposto, no que tange às exportações e importações, é importante notar que a presença da primeira contaminação apresenta contato com fatores exógenos ao respectivo município, pode ter alguma dependência do papel que os profissionais encarregados no trânsito de produtos podem exercer como vetores, de maneira que os distintos volumes de trânsito possam ter incorrido em variação da exposição dos municípios à primeira contaminação, ou, ainda, pode ser um fator relevante nos meses subsequentes ao período levantado. Reitera-se que as medidas de importação ou exportação, no entanto, têm limitações, pois não indicam mobilidade de cargas em transações internas.

\section{Difusão da COVID-19 entre os municípios segundo Medidas Aeroviárias, Hidroviárias e Rodoviárias}

Enquanto as medidas de exportação e importação não necessariamente se encontram diretamente ligadas à mobilidade de pessoas, visto que o aumento do volume de carga pode não corresponder a um aumento proporcional de pessoas que as conduzem, é adequado que sejam analisados dados de mobilidade de pessoas por meios aeroviário, hidroviário e rodoviário, uma vez que esses podem auxiliar a identificar as áreas em que existe maior risco de chegada da COVID-19 no contexto local, a partir de pessoas em trânsito nos aeroportos, nas rodoviárias e nos portos.

Como proxy do volume de pessoas em movimento nas rodoviárias e portos hidroviários, foi utilizado o índice de proximidade rodoviária/hidroviária (IBGE, 2016). No Brasil são 184 municípios com índice 0; 183 com índice de até 0,$2 ; 1.382$ municípios com índice entre 0,2 e 0,$25 ; 2.285$ municípios com índice entre 0,25 e 0,30; 1.332 municípios com índice entre 0,30 e 0,35; 189 com índice entre 0,4 e 0,5 e, por fim, 15 municípios com índice superior a 0,45. Para fins de entendimento do índice, cabe observar que São Paulo detém o maior, 0,56, o que significa que a capital paulista tem ligações de transporte

DOI: http://dx.doi.org/10.14393/Hygeia16055064 $\quad$ Hygeia $\quad$ v.16 $\quad$ p. $199-219,2020$ página 212


Pandemia e território: ritmo de difusão da Covid-19 entre municípios brasileiros de 25 de fevereiro a 11 de maio de 2020 de acordo com fatores de proximidade social extramunicipal
Augusto dos Santos Pereira Caroline Busatta Vaz de Paula Lucia de Noronha Eduardo Vedor de Paula

de passageiros com $56 \%$ dos nós da rede rodoviária do país (no caso dos municípios portuários ou de transporte intermunicipal via rios, como no Norte do país, esse indicador também se refere às ligações hidroviárias).

No Gráfico 8, observa-se que grupos de municípios com índice de proximidade mais elevado tendem a ter maior proporção interna de municípios afetados. Os 15 municípios com índice de proximidade acima de 0,45 se encontravam todos afetados pela COVID-19 ainda no mês de março. O grupo formado por aqueles em que o índice de proximidade era de 0,40 a 0,45 , contou com mais de $90 \%$ de seus 189 municípios afetados por COVID-19 (171 municípios) no último dia em análise. Dos 1.332 municípios com índices de proximidade entre 0,35 e 0,40, $864(65,6 \%)$ haviam sido afetados pela epidemia até o limite do período investigado.

\section{Gráfico 8 - Razão de municípios com casos notificados por total de municípios no Brasil, segundo índice de proximidade}

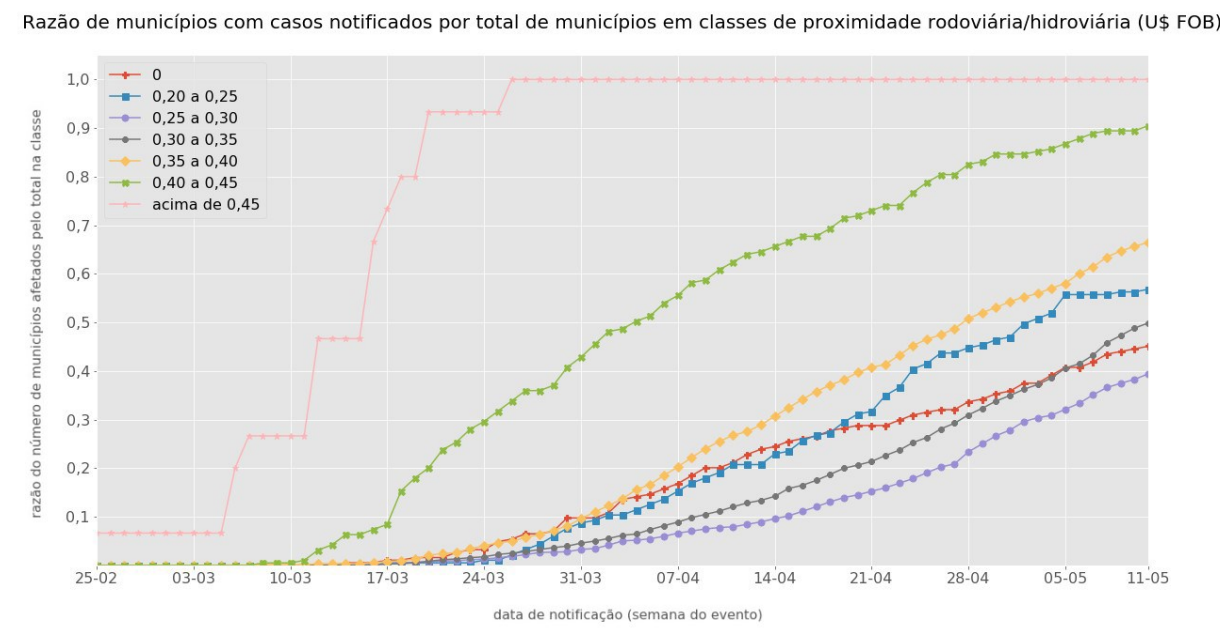

Fonte: Elaborado por Augusto dos Santos Pereira a partir de dados disponíveis em IBGE (2016) e COTA (2020) Nota: O gráfico ignora uma minoria de casos reportados nos quais não há identificação dos municípios.

Os grupos com menores níveis de proximidade apresentaram, de maneira geral, uma proporção menor dos seus municípios com casos confirmados, até a data limite do presente estudo, mas sem que fosse detectável uma relação linear entre diminuição do nível de proximidade na classe e a proporção de municípios afetados. Isso ocorre por conta de algumas particularidades das medidas de proximidade rodoviária. Na classe de municípios sem ligação rodoviária, por exemplo, vinte e nove dos oitenta e três municípios sem ligação rodoviária direta (índice 0) que apresentaram casos de COVID-19 estão ligados a metrópoles ou capitais regionais, de maneira que, embora não contem com sua própria rodoviária, encontram-se em áreas metropolitanas ou centralidades intermediárias servidas por elas.

Seguindo-se com a análise da relação entre o fluxo de pessoas e a difusão da epidemia, é possível analisar dados de número de passageiros em voos nacionais e internacionais, conforme apresenta o Gráfico 9.

Assim, para fins da presente pesquisa, no Brasil, somente vinte e cinco municípios contavam com voos internacionais, que, de maneira geral, fizeram parte das primeiras levas de municípios afetados, como é possível se observar no Gráfico 9. Dada a origem externa da COVID-19, é inegável o papel dos voos internacionais para a disseminação dos primeiros casos no país. De fato, todos os dezesseis municípios cujos aeroportos recebem mais de 20.000 passageiros internacionais por ano foram atingidos em menos de um mês do início do evento epidêmico. 
Pandemia e território: ritmo de difusão da Covid-19 entre municípios brasileiros de 25 de fevereiro a 11 de maio de 2020 de acordo com fatores de proximidade social extramunicipal
Augusto dos Santos Pereira Caroline Busatta Vaz de Paula Lucia de Noronha Eduardo Vedor de Paula

Gráfico 9 - Razão de municípios com casos notificados por total de municípios no Brasil, segundo classe de passageiros em voos internacionais

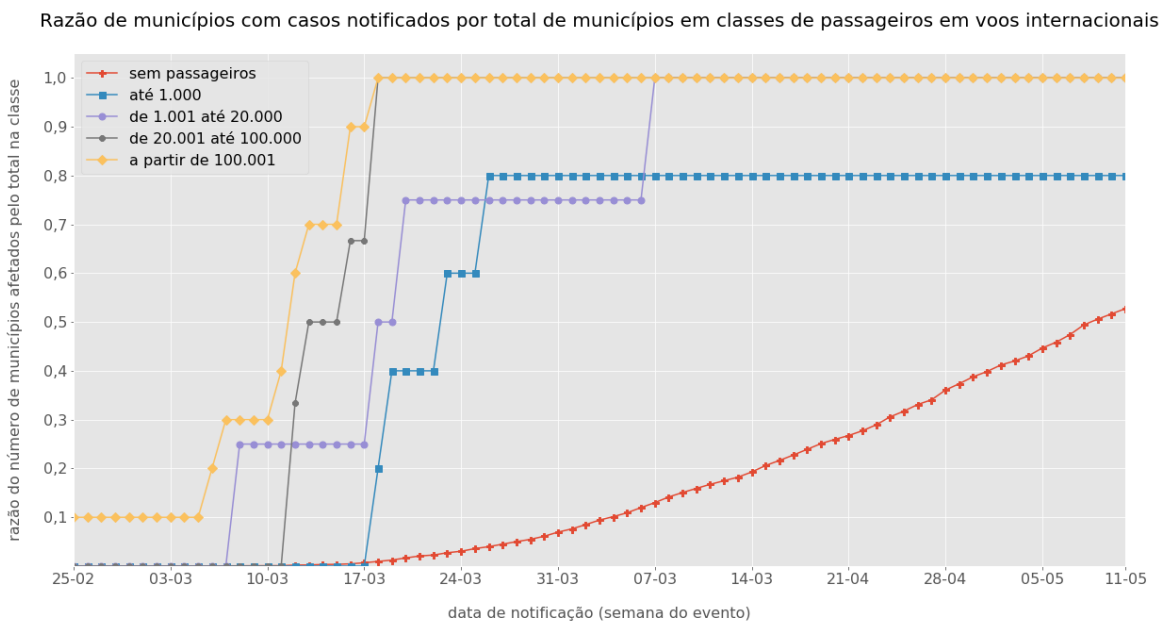

Fonte: Elaborado por Augusto dos Santos Pereira a partir de dados disponíveis em ANAC (2020) e COTA (2020) Nota: O gráfico ignora uma minoria de casos reportados nos quais não há identificação dos municípios.

O rol de municípios com voos domésticos é maior, com 159 no ano de 2019. Todos os dezenove municípios com trânsito de mais de 1 milhão de passageiros por ano foram atingidos até 20 de março. Na sequência, os trinta e um com trânsito de passageiros na ordem das centenas de milhares até um milhão foram atingidos até 08 de abril. As demais classes de municípios, conforme número de passageiros nacionais, também se destacam do comportamento daqueles municípios sem aeroportos - Gráfico 10.

Gráfico 10 - Razão de municípios com casos notificados por total de municípios no Brasil, segundo classe de passageiros em voos nacionais

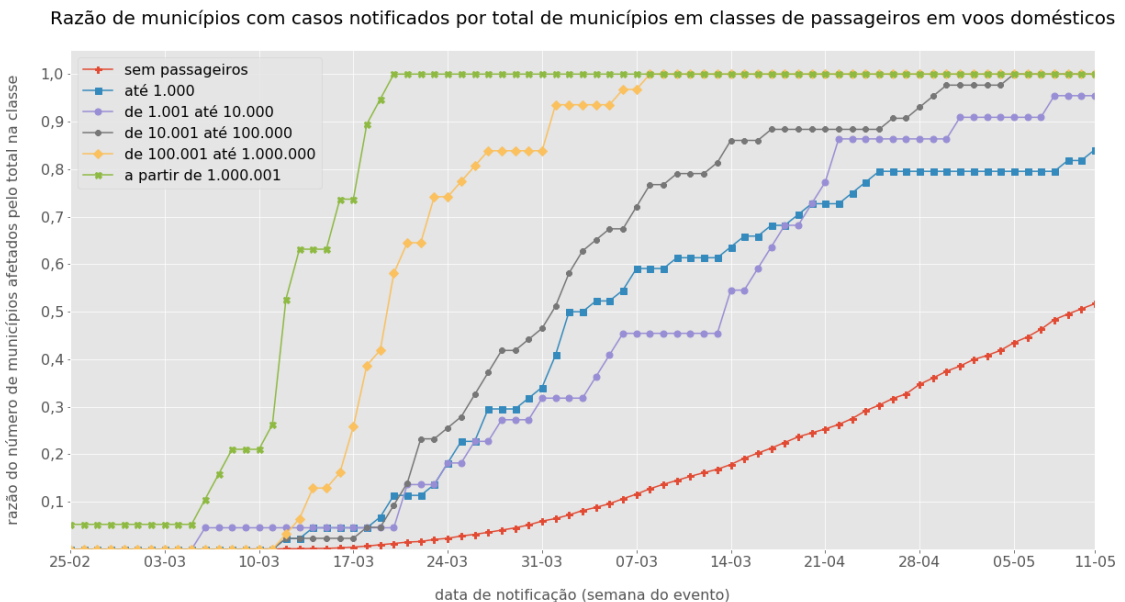

Fonte: Elaborado por Augusto dos Santos Pereira a partir de dados disponíveis em ANAC (2020) e COTA (2020) Nota: O gráfico ignora uma minoria de casos reportados nos quais não há identificação dos municípios.

Nota-se que as medidas de proximidade rodoviária-hidroviária e as de número de passageiros em voos internacionais ou domésticos apresentam uma grande relação com o processo de difusão da COVID-19 entre municípios brasileiros. É possível que medidas de restrição à mobilidade das 
Pandemia e território: ritmo de difusão da Covid-19 entre municípios brasileiros de 25 de fevereiro a 11 de maio de 2020 de acordo com fatores de proximidade social extramunicipal
Augusto dos Santos Pereira Caroline Busatta Vaz de Paula Lucia de Noronha

Eduardo Vedor de Paula

empresas de transporte rodoviário e hidroviário tomadas no Brasil tenham surtido algum efeito no processo de difusão municipal da COVID-19. Ainda assim, o monitoramento futuro desses indicadores pode ser relevante, sobretudo em momentos de relaxamento das estratégias de distanciamento/isolamento social.

\section{Difusão da COVID-19 entre os municípios segundo Classes de Relevância do Turismo}

O turismo, por sua intrínseca ligação com a mobilidade de pessoas, seja para fins de lazer ou negócios, seguramente tem um efeito importante na forma como ocorre a difusão territorial de uma epidemia da magnitude da COVID-19. Por essa razão, adiante é apresentada a relação entre classes de municípios segundo competitividade para o turismo e a evolução das notificações de COVID-19.

No ano de 2019, 2.694 municípios com alguma participação no setor de turismo foram classificados segundo níveis de relevância, enquanto os 2.876 municípios restantes não apresentaram participação notável a ponto de entrarem no estudo do Ministério do Turismo (2019). A classe A, a mais alta, tinha 62 municípios; a B, 257; a C, 475; a D, 1522; e a E, 377.

O Gráfico 11 mostra que é muito alta a correlação entre as classes de turismo e a proporção de municípios afetados pela COVID-19, no período em análise, em que pese o fato de os municípios sem classificação terem maior participação tanto relativa como absoluta, quando comparados com os municípios de classe de competitividade $\mathrm{E}$.

\section{Gráfico 11 - Razão de municípios com casos notificados por total de municípios no Brasil, segundo} classes de relevância do Turismo

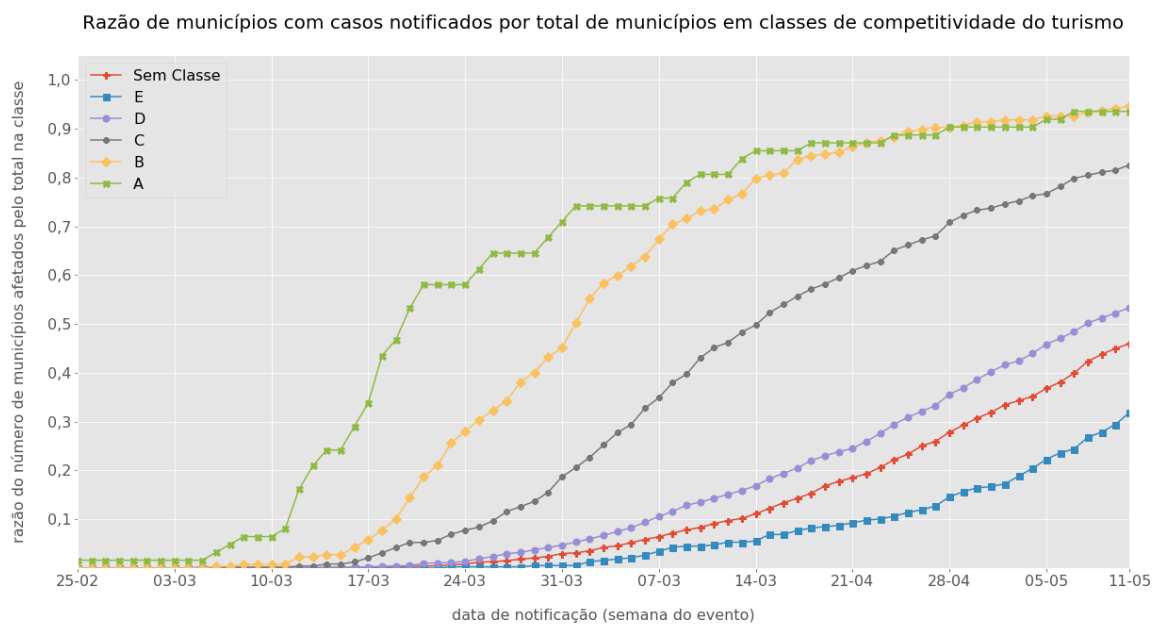

Fonte: Elaborado por Augusto dos Santos Pereira a partir de dados disponíveis em MINISTÉRIO DO TURISMO (2019) e COTA (2020)

Nota: O gráfico ignora uma minoria de casos reportados nos quais não há identificação dos municípios.

Ressalta-se que o turismo é um indicador que aponta para a relevância de um acompanhamento de diferentes fatores no monitoramento da difusão territorial da COVID-19. Isso porque, ao mesmo tempo que aponta para os mesmos casos já identificados por outras medidas (como População, PIB e hierarquia urbana), destacando-se como elevados os casos de São Paulo, Rio de Janeiro, Salvador entre outros, também aponta para a relevância de municípios não evidenciados por aqueles indicadores. Assim, os municípios como llha Bela (SP), Porto Seguro (BA) e Caldas Novas (GO), entre outros, que não se encontram no topo de qualquer outra medida levantada até agora, apresentam no turismo um elemento relevante, por comporem índice A de competitividade. É razoável reconhecer, portanto, que as medidas sobre turismo, conjugadas a outras, conformam indicadores importantes para a categorização dos municípios com maior suscetibilidade à apresentação/ocorrência de casos de COVID-19. 
Pandemia e território: ritmo de difusão da Covid-19 entre municípios brasileiros de 25 de fevereiro a 11 de maio de 2020 de acordo com fatores de proximidade social extramunicipal
Augusto dos Santos Pereira Caroline Busatta Vaz de Paula Lucia de Noronha Eduardo Vedor de Paula

\section{Classes de Municípios Segundo Grau de Exposição ao Risco Decorrente de Proximidade Social Extramunicipal}

No período avaliado, os dados apontam para uma difusão com ritmos distintos da epidemia entre os municípios, de maneira que alguns grupos podem ser identificados. O primeiro deles, é um grupo de municípios com elevada exposição ao risco de inserção do vírus no contexto comunitário, visto que contou com substantivo número de municípios com casos já no primeiro mês da difusão. Esses municípios apresentam uma ou mais das seguintes características: elevada ou intermediária hierarquia urbana (polos metropolitanos e integrantes dos espaços metropolitanos, bem como capitais regionais ou até centros sub-regionais); com população a partir de 500 mil habitantes; com PIB a partir de R $\$ 5$ bilhões; ou com importações acima de R\$ 200 milhões; com índice de proximidade rodoviária/hidroviária acima de 0,45; acima de 20.000 passageiros por ano em voos internacionais de seus aeroportos; acima de 100.000 passageiros em voos domésticos; classe A de competitividade do turismo.

Outro grupo identificável é formado por municípios cuja participação relativa entre aqueles com casos de COVID-19 cresceu significativamente a partir do vigésimo dia da primeira notificação no país. Esses municípios apresentam as seguintes características, não necessariamente concomitantes: centros de zona A ou centros sub-regionais B; municípios com mais de 50 mil até 500 mil habitantes; PIB entre $R \$ 1$ e $R \$ 5$ bilhões, importações entre $R \$ 10$ e $R \$ 200$ milhões; índice de proximidade entre 0,4 e 0,45 ; até 20.000 passageiros em voos internacionais; acima de 10.000 até 100.000 passageiros em voos domésticos; classe $B$ de turismo.

Um terceiro grupo é formado por centros de zona B; população entre 20.000 e 50.000 habitantes; entre $R \$ 500$ milhões e $R \$ 1,0$ bilhão de PIB; importações entre $R \$ 50$ mil até $R \$ 10$ milhões; classe de proximidade abaixo de 0,4 - abaixo desse limiar, não se evidencia um padrão claro para delimitação de grupos de municípios com diferentes níveis de suscetibilidade, por essa razão, as duas classes de menor suscetibilidade apresentadas não são diferenciadas por esse parâmetro; com aeroporto em que circulam até 10 mil passageiros em voos domésticos, mas sem viagens internacionais de passageiros; nível $\mathrm{C}$ de competitividade de turismo $\mathrm{C}$.

Por fim, os municípios que tiveram menor suscetibilidade relativa ao longo do período, foram aqueles com: hierarquia urbana de centro local; PIB abaixo de R $\$ 500$ milhões, sem importações ou com importações com valor de até $R \$ 50$ mil em 2019, sem aeroporto com viagens internacionais ou nacionais; competitividade de turismo $\mathrm{D}$ ou sem ranqueamento no tema.

\section{CONSIDERAÇÕES FINAIS}

O presente trabalho buscou entender de que forma fatores de proximidade social extramunicipal condicionam o grau de exposição das populações nos diferentes municípios brasileiros ao risco de contaminação por SARS-CoV-2. Para tanto, baseou-se em matriz teórica que considera que condições sociais, ambientais e etiológicas, combinadamente, conformam fatores explicativos das difusões de doenças infectocontagiosas, o que reafirma a importância do conceito de espaço geográfico na análise de difusão desse tipo de doenças, em geral, e da COVID-19, especificamente. Nesse interim, considerando-se as evidências da proximidade social como fator relevante em sua disseminação, foram buscados dados sobre fatores de proximidade social extramunicipal, ou seja, de elementos que indiquem que indivíduos pertencentes à população de determinado município tenham maior probabilidade de interação com indivíduos não-residentes, com origens em outros municípios ou mesmo no exterior. Os dados escolhidos (hierarquia urbana, patamar populacional, produção de riqueza, trânsito de mercadorias, transporte de passageiros e turismo) foram comparados com aqueles de data notificação do primeiro caso em cada município brasileiro.

Os resultados mostram que, com diferentes intensidades, esses fatores de proximidade social extramunicipal estão associados a diferentes graus de exposição das populações nos municípios ao risco de introdução de SARS-CoV-2 ao longo do tempo. Em cada município, os primeiros casos podem resultar da exposição à contaminação, o que resulta de diversas dinâmicas sociais: trânsito de turistas, pessoas de classe média, que estão voltando de férias alhures, caminhoneiros com mercadorias em trânsito etc. Não há como identificar qual a participação de cada um desses fatores na efetiva chegada dos primeiros casos entre residentes nos municípios. Por essa razão, as medidas de hierarquia urbana, de concentrações populacional e econômica, de integração por fluxos de pessoas e de atração para o turismo apresentadas parecem servir como identificação de distintos patamares de participação dos municípios nos fluxos intermunicipais, regionais, nacionais e globais, 
Pandemia e território: ritmo de difusão da Covid-19 entre municípios brasileiros de 25 de fevereiro a 11 de maio de 2020 de acordo com fatores de proximidade social extramunicipal
Augusto dos Santos Pereira Caroline Busatta Vaz de Paula Lucia de Noronha Eduardo Vedor de Paula

que, em suas crescentes escalas de grandeza, relacionam-se com um menor ou maior grau de exposição da população à introdução local do vírus.

Em meio a um contexto de crescente integração territorial, para além dos eixos mais dinâmicos do Centro-Sul, a difusão geográfica da COVID-19 no Brasil se mostra como um fenômeno com potencial para alcançar todos os municípios do país. O processo ocorre, porém, com suas particularidades, de forma que a difusão se dá por uma espécie de distância topológica, em que fatores de integração e mobilidade populacional, níveis de centralidade, trânsito de pessoas para transporte de produtos, concentração populacional e econômica, bem como destaque nos serviços de turismo criam condições para maior risco à manifestação da doença dentro dos territórios municipais de destaque, a partir dos quais se disseminam para os municípios de seu entorno mais próximo, em que a lógica topológica se associa à proximidade euclidiana e ao avizinhamento.

Esse tipo de medida em fração de grupos de municípios atingidos e as cinco classes municipais obtidas podem servir para a elaboração de índice de suscetibilidade municipal a contaminações externas por COVID-19, representando um dado de probabilidade variável no tempo.

É possível que o papel de diversos desses fatores aqui levantados tenham comportamentos distintos ao longo do tempo, de maneira que, em um primeiro momento, a mobilidade de passageiros internacionais, sobretudo em cruzeiros e aeroportos, tenha tido maior relevância na difusão da epidemia nas primeiras semanas, enquanto outras mobilidades (de prestadores de serviços de entrega, de viajantes em transporte rodoviário, hidroviário e aeroviário de passageiros domésticos) passem a ter maior relevância ao longo do tempo, o que torna o monitoramento da expansão da epidemia em face das métricas aqui apresentadas um procedimento viável de subsídio às políticas de contenção, às estratégias de distanciamento/isolamento social e às futuras fases de abertura.

Outros indicadores não adotados no presente trabalho podem contribuir para melhores resultados explicativos e para o monitoramento. Em lugar do PIB per capita, por exemplo, a renda média das famílias pode ser um elemento de elevada importância, uma vez que os primeiros casos tiveram muita associação com viajantes internacionais, mais comuns entre os extratos socioeconômicos mais altos. Da mesma forma, os estudos sobre aglomerados populacionais podem ajudar a identificar classes de municípios com maior integração por pendularidade populacional, que, porventura, componham distintos níveis de suscetibilidade.

Cabe destacar que, ao menos com os dados considerados, os cinco grupos resultantes dificilmente poderiam ser operacionalizados a contento por técnicas tradicionais de análise de clusters, ou exigiriam procedimentos bastante custosos de engenharia de atributos - feature engineering -, uma vez que muitos municípios com características significativamente diferentes foram atingidos a cada semana do evento epidêmico, o que seria tomado como "ruído" por esses modelos. Dessa forma, o procedimento aqui adotado, pela avaliação da relação de cada fator com o ritmo de exposição relativa dos municípios aos primeiros casos notificados, parece contornar esse tipo de limitação.

\section{REFERÊNCIAS}

ANAC. Agência Nacional De Aviação Civil. Dados e Estatísticas. Brasília: ANAC, 2020.Disponível em: https://www.anac.gov.br/assuntos/dados-e-estatisticas. Acesso em: 26 mar. 2020.

BARRASA, H.; RELLO, J.; TEJADA, S.; MARTÍN, A.; BALZISKUETA, G.; VINUESA, C.; FERNÁNDEZMIRET, B.; VILLAGRA, A.; VALLEJO, A.; SAN SEBASTIÁN, A.; CABAÑES, S.; IRIBARREN, S.; FONSECA, F.; MAYNAR, J., ALAVA COVID-19 STUDY INVESTIGATORS (2020). SARS-CoV-2 in Spanish Intensive Care Units: Early experience with 15-day survival in Vitoria. Anaesthesia Critical Care and Pain Medicine, [S. I.], p. 1-9, 2020. https://doi.org/10.1016/j.accpm.2020.04.001

BBC NEWS. Coronavirus: Hard-hit Brazil removes data amid rising death toll. Disponível em: https://www.bbc.com/news/world-latin-america-52952686. Acesso em: 20 jun. 2020.

BERRY, B. J. L.; GARRISON, W. L. The Functional Bases of the Central Place Hierarchy. Economic Geography, [S. I.], v. 34, n. 2, p. 145-154, 1958. DOI: 10.2307/142299. Disponível em: https://www.tandfonline.com/doi/abs/10.2307/142299. Acesso em: 20 dez. 2017. https://doi.org/10.2307/142299

BULUT, C.; KATO, Y. Epidemiology of covid-19. Turkish Journal of Medical Sciences, [S. I.], v. 50, n. SI1, p. 563-570, 2020. https://doi.org/10.3906/sag-2004-172 
Pandemia e território: ritmo de difusão da Covid-19 entre municípios brasileiros de 25 de fevereiro a 11 de maio de 2020 de acordo com fatores de proximidade social extramunicipal
Augusto dos Santos Pereira Caroline Busatta Vaz de Paula Lucia de Noronha Eduardo Vedor de Paula

CHRISTALLER, W. Die zentralen Orte in Suddeutschland. Jena: Gustav Fischer, 1933.

COSSARIZZA, A.; DE BIASI, S.; GUARALDI, G.; GIRARDIS, M.; MUSSINI, C.; MODENA COVID-19 WORKING GROUP (MOCO19). SARS-CoV-2, the Virus that Causes COVID-19: Cytometry and the New Challenge for Global Health.Cytometry. Part A: the journal of the International Society for Analytical Cytology, 2020. https://doi.org/10.1002/cyto.a.24002

COTA, W. Número de casos confirmados de COVID-19 no Brasil. Viçosa: UFV, 2020. Disponível em: https://labs.wesleycota.com/sarscov2/br/\#municipio. Acesso em: 27 mar. 2020.

ECDC. European Center for Disease Prevention and Control. Situation update worldwide. Estocolmo: ECDC, 2020. Disponível em: https://www.ecdc.europa.eu/en/geographical-distribution-2019-ncov-cases. Acesso em: 25 abr. 2020.

GE, H.; WANG, X.; YUAN, X.; XIAO, G.; WANG, C.; DENG, T.; YUAN, Q.; XIAO, X. The epidemiology and clinical information about COVID-19. European journal of clinical microbiology \& infectious diseases: official publication of the European Society of Clinical Microbiology, [S. I.], v. 39, n. 6, p. 1011-1019, 2020. https://doi.org/10.1007/s10096-020-03874-z

HUANG, X.; WEI, F.; HU, L.; WEN, L.; CHEN, K. Epidemiology and Clinical Characteristics of COVID-19. Archives of Iranian medicine, Iran, v. 23, n. 4, p. 268-271, 2020. https://doi.org/10.34172/aim.2020.09.

IBGE. Instituto Brasileiro de Geografia e Estatística. Tabela 5938 - Produto interno bruto a preços correntes. Rio de Janeiro: IBGE/CDDI, 2017. Disponível em: https://sidra.ibge.gov.br/tabela/5938. Acesso em: 27 mar. 2020.

IBGE. Instituto Brasileiro de Geografia e Estatística. Estimativas da População - Estima Pop. Rio de Janeiro: IBGE/CDDI, 2019. Disponível em: https://sidra.ibge.gov.br/pesquisa/estimapop/tabelas. Acesso em: 27 mar. 2020.

IBGE. Instituto Brasileiro de Geografia e Estatística. Malhas Municipais. Rio de Janeiro: IBGE/DEGEO, 2018.

ftp://geoftp.ibge.gov.br/organizacao do territorio/malhas territoriais/malhas municipais/. Acesso em: 27 mar. 2020.

IBGE. Instituto Brasileiro de Geografia e Estatística. REGIC - Pesquisa de Ligações rodoviárias e hidroviárias. Rio de Janeiro: IBGE/CDDI, 2016. Disponível em: https://biblioteca.ibge.gov.br/index.php/biblioteca-catalogo?view=detalhes\&id=2100617. Acesso em: 27 mar. 2020.

INFOGRIPE. Situação da gripe. Rio de Janeiro: FioCruz, 2020. Disponível em: http://info.gripe.fiocruz.brl. Acesso em: 24 mai. 2020.

HEROY, S. Metropolitan-scale COVID-19 outbreaks: how similar are they? [S. I.], 2020. Disponível em: https://arxiv.org/abs/2004.01248. Acesso em: Acesso em: 22 jun. 2020.

JUNQUEIRA, R. D. Geografia Médica E Geografia Da Saúde. HYGEIA, Revista Brasileira de Geografia Médica e da Saúde, [S. I.], v. 5, n. 8, p. 1-10, 2009.

LANA, R. M.; COELHO, F.C.; COSTA GOMES, M. F.; CRUZ, O. G.; BASTOS, L. S.; VILLELA, D. M. The novel coronavirus (SARS-CoV-2) emergency and the role of timely and effective national health surveillance. Cadernos de saude publica, Brazil, v. 36, n. 3, p. e00019620, 2020. https://doi.org/10.1590/0102-311x00019620

LEMOS, J. C. INSTITUTO, Prof; UFU, De Geografia. a Geografia Médica E As Doenças InfectoParasitárias. Medicina, [S. I.], p. 74-86, 2002.

LEWNARD, J. A.; LO, N. C. Scientific and ethical basis for social-distancing interventions against COVID19.The Lancet Infectious Diseases,v.20, n.6, p.631-633, 2020. DOI: 10.1016/S1473-3099(20)30190-0. Disponível em:https://pubmed.ncbi.nlm.nih.gov/32213329/. Acesso em: 22 jun. 2020. https://doi.org/10.1016/S1473-3099(20)30190-0

LIU, T.; HU, J.; KANG, M.; LIN, L.; ZHONG, H.; XIAO, J.; HE, G.; SONG, T.; HUANG, Q.; RONG, Z.; DENG, A.; ZENG, D.; TAN, X.; ZENG, S.; ZHU, Z.; LI, J.; WAN, D.; LU, J.; DENG, H.; HE, D.; MA, W. Transmission dynamics of 2019 novel coronavirus (2019-nCoV). bioRxiv, [S. I.], p. 2020.01.25.919787, 2020. DOI: $\quad 10.1101 / 2020.01 .25 .919787 . \quad$ Disponível em: 
Pandemia e território: ritmo de difusão da Covid-19 entre municípios brasileiros de 25 de fevereiro a 11 de maio de 2020 de acordo com fatores de proximidade social extramunicipal
Augusto dos Santos Pereira Caroline Busatta Vaz de Paula Lucia de Noronha Eduardo Vedor de Paula

http://biorxiv.org/content/early/2020/01/26/2020.01.25.919787.abstract. Acesso em 21 jun. 2020.

MDIC. Ministério Da Economia, Indústria, Comércio Exterior E Serviços. Exportações e Importações Municípios. Brasília: COMEX-STAT, 2020. Disponível em: https://comextat.medic.gov.br. Acesso em: 11 mai. 2020.

MS. Ministério Da Saúde. Painel Coronavírus. Brasília: MS, 2020. Disponível em: https://covid.saude.gov.br/. Acesso em: 11 mai. 2020.

MINISTÉRIO DO TURISMO. Índice de Competitividade 2015. Brasília: MINT, 2015. Disponível em: http://dados.turismo.gov.br/indice-de-competitividade. Acesso em: 23 mar. 2020.

MINISTÉRIO DO TURISMO. Portaria 144. Brasília: MINT, 2015. Disponível em: http://www.turismo.gov.br/legislacao/?p=822. Acesso em: 23 mar. 2020.

ONU. Organização Das Nações Unidas -. A UN framework for the immediate socio-economic response to COVID-19. Nova lorque: UNDP, 2020. Disponivel em: https://www undp.org/. Acesso em: 20 jun. 2020.

OMS. Organização Mundial Da Saúde - Novel Coronavirus (2019-nCoV) SITUATION REPORT - 1. 21 Jan. 2020a, disponível em https://www.who.int/emergencies/diseases/novel-coronavirus-2019/situationreports. Acesso em: 23 jun. 2020.

OMS. Organização Mundial Da Saúde - Novel Coronavirus (2019-nCoV) SITUATION REPORT - 122. 11 mai. 2020b, disponível em https://www.who.int/emergencies/diseases/novel-coronavirus-2019/situationreports. Acesso em: 23 jun. 2020.

OMS. Organização Mundial Da Saúde - Novel Coronavirus (2019-nCoV) SITUATION REPORT - 72. 1 abr. 2020c, disponível em https://www.who.int/emergencies/diseases/novel-coronavirus-2019/situationreports. Acesso em: 23 jun. 2020.

PEREIRA, A. S. Estudo sobre disseminação da COVID-19 no Brasil. Github, 2020. Disponível em: <github.com/augustogeog/covid?files=1>. Acesso em: 20 jun. 2020.

PORTAL SINAN. Disponível em:

https://portalsinan.saude.gov.br/images/documentos/Calendario/2020.pdf. Acesso em 25 mai.2020.

READ, J. M.; BRIDGEN, J. R. E.; CUMMINGS, D. A. T.; HO, A.; JEWELL, C. P. Novel coronavirus 2019nCoV: early estimation of epidemiological parameters and epidemic predictions. medRxiv, [S. I.], p. 2020.01.23.20018549, 2020. DOI: 10.1101/2020.01.23.20018549. Disponível em: http://medrxiv.org/content/early/2020/01/28/2020.01.23.20018549.abstract. Acesso em 19 de jun. 2020.

ROCHEFORT, M. M. A concepção geográfica da polarização regional. São Paulo: Difusão Europeia do Livro, 1966.

ROTHAN, H. A.; BYRAREDDY, S. N. The epidemeology and pathogensis of coronavirus (Covid-19) outbreak. Journal of Autoimmunity, [S. I.], v. 109, n. January, p. 1-4, 2020. https://doi.org/10.1016/j.jaut.2020.102433

SANTOS, Milton. Por uma Geografia Nova. São Paulo: Hucitec, 1978.

SILVA, L. J. O conceito de espaço na epidemiologia das doenças infecciosas. Cadernos de Saúde Pública, [S. I.], v. 13, n. 4, p. 585-593, 1997. DOI: 10.1590/s0102-311x1997000400002. Disponível em: https://www.scielo.br/pdf/csp/v13n4/0143pdf. Acesso em: 22 jun. 2020. https://doi.org/10.1590/S0102311X1997000400002

VELAVAN, T. P.; MEYER, C. G. The COVID-19 epidemic.Tropical medicine \& international health: TM \& IH, 2020. https://doi.org/10.1111/tmi.13383

WHO. World Healty Organization. Coronavirus Disease (COVID-19) Situation Reports. [s.d.]. Disponível em: https://www.who.int/emergencies/diseases/novel-coronavirus-2019/situation-reports. Acesso em: 17 jun. 2020.

ZHANG, T.; SUN, L. X.; FENG, R. E. Comparison of clinical and pathological features between severe acute respiratory syndrome and coronavirus disease 2019. Zhonghua jie he he hu xi za zhi = Zhonghua jiehe he huxi zazhi $=$ Chinese journal of tuberculosis and respiratory diseases, China, v. 43, n. 6 , p. 496-502, 2020. DOI: 10.3760/cma.j.cn112147-20200311-00312. 